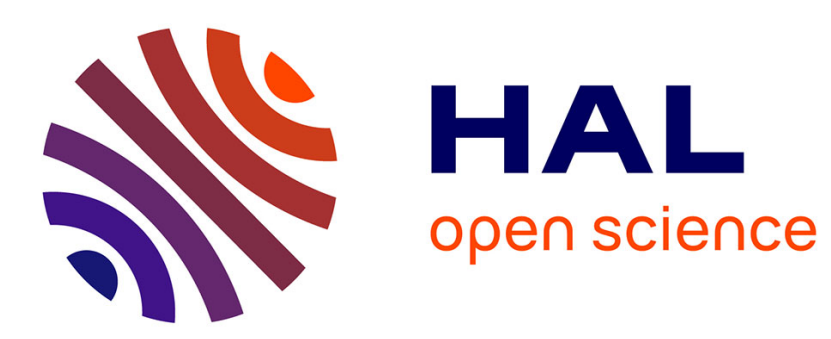

\title{
Workaholism profiles: Associations with determinants, correlates, and outcomes
}

Nicolas Gillet, Alexandre J.S. Morin, Baptiste Cougot, Marylène Gagné

\section{To cite this version:}

Nicolas Gillet, Alexandre J.S. Morin, Baptiste Cougot, Marylène Gagné. Workaholism profiles: Associations with determinants, correlates, and outcomes. Journal of Occupational and Organizational Psychology, 2017, 90 (4), pp.559-586. 10.1111/joop.12185 . hal-03175206

\section{HAL Id: hal-03175206 https://hal.science/hal-03175206}

Submitted on 19 Mar 2021

HAL is a multi-disciplinary open access archive for the deposit and dissemination of scientific research documents, whether they are published or not. The documents may come from teaching and research institutions in France or abroad, or from public or private research centers.
L'archive ouverte pluridisciplinaire HAL, est destinée au dépôt et à la diffusion de documents scientifiques de niveau recherche, publiés ou non, émanant des établissements d'enseignement et de recherche français ou étrangers, des laboratoires publics ou privés. 
Running Head: Workaholism Profiles

\title{
Workaholism Profiles: Associations with Determinants, Correlates, and Outcomes
}

\author{
Nicolas Gillet $^{1 *}$, Alexandre J. S. Morin ${ }^{2}$, Baptiste Cougot ${ }^{1}, \&$ Marylène Gagné ${ }^{3}$ \\ ${ }^{1}$ Université François-Rabelais de Tours, France \\ ${ }^{2}$ Concordia University, Canada \\ ${ }^{3}$ University of Western Australia, Australia
}

\begin{abstract}
* Corresponding author
Nicolas Gillet,

Université François-Rabelais de Tours,

UFR Arts et Sciences Humaines,

Département de psychologie,

3 rue des Tanneurs, 37041 Tours Cedex 1, France.

E-mail: nicolas.gillet@univ-tours.fr
\end{abstract}

This is the prepublication version of the following manuscript:

Gillet, N., Morin, A. J. S., Cougot, B., \& Gagné, M. (in press). Workaholism profiles: Associations with determinants, correlates, and outcomes. Journal of Occupational and Organizational Psychology. Early view. doi: 10.1111/joop.12185.

(C) 2017. This paper is not the copy of record and may not exactly replicate the authoritative document published in Journal of Occupational and Organizational Psychology.

\begin{abstract}
The present series of studies examines how the two dimensions of workaholism (working excessively and compulsively) combine within different profiles of workers. This research also documents the relations between these workaholism profiles and a series of correlates (psychological need thwarting) and adaptive and maladaptive work outcomes. In addition, this research investigates the role of emotional dissonance and employees' perceptions of their workplaces' psychosocial safety climate (Study 1, $\mathrm{n}=465$ ), as well as job demands, resources, and perfectionism (Study 2, $\mathrm{n}=780$ ) in the prediction of profile membership. Latent profile analysis revealed four identical workaholism profiles in both studies. In Study 1, emotional dissonance predicted a higher likelihood of membership in the Very High, Moderately High, and Moderately Low profiles relative to the Very Low profile. In contrast, Study 2 revealed a more diversified pattern of predictions. In both studies, levels of need thwarting were the highest in the Very High and Moderately High profiles, followed by the Moderately Low profile, and finally by the Very Low profile. Finally, in both studies, the most desirable outcomes levels (e.g., lower levels of work-family conflict and emotional exhaustion, and higher levels of perceived health) were associated with the Very Low profile, followed by the Moderately Low profile, then by the Moderately High profile, and finally by the Very High profile.
\end{abstract}

Keywords: Workaholism profiles; Working excessively and compulsively; Job demands and resources; Health; Psychological needs 
Oates (1971) defined workaholism as "the compulsion or the uncontrollable need to work incessantly" (p. 1). Machlowitz (1980) added that workaholics tend to allocate as much time as possible to work. Indeed, scholars (e.g., Schaufeli, Bakker, van der Heijden, \& Prins, 2009; Schaufeli, Shimazu, \& Taris, 2009) generally propose to differentiate the behavioral (i.e., being hardworking, spending a great deal of time in work activities, neglecting other spheres of life) and cognitive (i.e., being obsessed with work, thinking compulsively about work) facets of workaholism. Recently, research has started to examine how these two facets combine within specific individuals (Kravina, Falco, Girardi, \& De Carlo, 2010; Schaufeli, Bakker et al., 2009). Variable-centered analyses, designed to test how specific variables relate to other variables are able to tests for interactions among predictors (i.e., if the effect of a predictor differs as a function of another variable). However, through their focus on the identification of subgroups characterized by distinct configurations, or profiles, on a set of variables, person-centered analyses are more naturally suited to the consideration of the joint effect of variable combinations. The present research extends prior studies of workaholism profiles (e.g., Buelens \& Poelmans, 2004) by (1) simultaneously and exclusively considering the two behavioral (working excessively) and cognitive (working compulsively) facets of workaholism, rather than relying on a mixture of indicators conflating workaholism facets with other variables; (2) assessing the construct validity of the workaholism profiles through the consideration of correlates, predictors, and a wide range of attitudinal and health outcomes; and (3) relying on state-of-the art latent profile analyses (LPA) rather than cluster analyses which have been criticized (see Meyer \& Morin, 2016), particularly for research involving covariates. Meyer and Morin (2016) emphasize the importance of clear a priori specifications of which covariates can be assumed to predict profile membership (predictors), to be predicted by it (outcomes), or to relate to the profiles with no assumption of directionality (correlates). However, although our treatment of covariates as correlates, determinants, and outcomes is theoretically anchored (Clark, Michel, Zhdanova, Pui, \& Baltes, 2016; Schaufeli, Bakker et al., 2009) and necessary for methodological reasons, our cross-sectional design precludes interpretations regarding the directionality of the associations.

\section{Workaholism}

Workaholism can be seen as an addiction to work (e.g., Schaufeli, Shimazu, \& Taris, 2009; Spence \& Robbins, 1992), leading to preoccupations and compulsions regarding work, loss of selfcontrol, and continued work engagement despite negative outcomes $(\mathrm{Ng}$, Sorensen, \& Feldman, 2007). Workaholic behaviors thus involve an excessive involvement in work that goes well beyond normal job requirements. Workaholics are also constantly obsessed with work, even when they are not working (Schaufeli, Bakker et al., 2009). These two behavioral and cognitive facets of workaholism (working excessively and compulsively) are not mutually exclusive, but rather seen as complementary and co-existing to various degrees within individuals (Clark et al., 2016). It thus follows that workaholism cannot be reduced to either of these two components. However, many studies have shown that the two dimensions of workaholism tend to be positively and moderately to strongly related (e.g., Huyghebaert et al., 2016), leaving as an open research question whether these two forms of workaholism really represent distinct components.

So far, the predictive validity of working excessively and compulsively has been documented in relation to a variety of work outcomes in the context of variable-centered studies (for a meta-analysis, see Clark et al., 2016). For instance, working compulsively and excessively both share positive relations with employees' levels of emotional exhaustion, presenteeism, and work-family conflict, as well as negative relations with happiness and performance (Huyghebaert et al., 2016; Schaufeli, Bakker et al., 2009). However, limited research has looked at the combined effects of these two dimensions of workaholism on these important work-related outcomes. Interestingly, emerging person-centered research suggests that employees characterized by a high level on both dimensions tend to experience fewer sleeping hours and poorer sleep quality on weekdays and weekends, relative to those scoring high on only one dimension (Salanova et al., 2016).

\section{Workaholism Profiles}

Variable-centered approaches examine relations occurring between variables, on the average, in a specific sample. In contrast, person-centered approaches identify homogeneous subgroups (or profiles) of workers sharing similar configurations of workaholism components. Therefore, the person-centered approach provides a complementary-yet uniquely informative - perspective on the same questions, focusing on individual profiles rather than on specific relations among variables (Marsh, Lüdtke, 
Trautwein, \& Morin, 2009; Morin \& Wang, 2016). In particular, person-centered analyses are naturally suited to the verification of how the two types of workaholism will be combined among different profiles of employees, and the relative consequences of membership into these various profiles. However, little person-centered research has been conducted on workaholism. Among the few available studies, Salanova, Del Libano, Llorens, and Schaufeli (2014) examined different profiles of wellbeing at work and identified a workaholic profile corresponding to employees characterized by moderate to high levels of energy, challenge, skills and identification, and by low levels of pleasure. Other investigations relied on a mixture of workaholism dimensions and additional constructs (Buelens \& Poelmans, 2004; Spence \& Robbins, 1992), making it impossible to identify workaholism configurations occurring independently from these additional dimensions.

Among the few relevant investigations, and despite some variations, four workaholism profiles have typically been identified (Kravina et al., 2010; Salanova et al., 2016): high levels of working compulsively and excessively (HC-HE), high levels of working compulsively and low levels of working excessively (HC-LE), low levels of working compulsively and high levels of working excessively (LC-HE), and low levels of working compulsively and excessively (LC-LE). For instance, Schaufeli, Bakker et al. (2009) identified these four workaholism profiles and showed the HC-HE profile to be associated with the most unfavorable outcomes in terms of mental health (i.e., burnout, happiness, and recovery) and organizational behaviors (i.e., presenteeism and performance) (also see Kravina et al., 2010). The reliance on cluster analyses is a key limitation of these studies. Indeed, cluster analyses have been previously criticized as showing a greater level of reactivity to the retained clustering algorithm, relying on rigid statistical assumptions, forcing the exact assignment of participants into a single profile (rather than taking into account participants' likelihood of membership in all profiles based on their prototypical similarity), and making it impossible to directly incorporate covariates into the model as predictors, correlates, or outcomes (for details, see Meyer \& Morin, 2016; Morin, Morizot, Boudrias, \& Madore, 2011).

The first purpose of the present research was thus to identify workaholism profiles using LPA, while simultaneously and exclusively considering the two facets of workaholism proposed by Schaufeli, Shimazu, and Taris (2009). To the best of our knowledge, no research has yet relied on LPA to identify workaholism profiles. Still, in line with past cluster analytic studies, it was expected that a relatively small number of profiles (i.e., between four and five) corresponding to the four previously identified configurations (1. HC-HE; 2. LC-LE; 3. HC-LE; 4. LC-HE) would be identified.

\section{Determinants of Workaholism Profiles}

Little research has investigated the structural determinants of workaholism profiles (Caesens, Stinglhamber, \& Luypaert, 2014). The job demands-resources model (Bakker \& Demerouti, 2007; Bakker, Demerouti, \& Euwema, 2005) classifies job characteristics in two general categories, job demands and job resources, providing an overarching model applicable to any work contexts. Job demands refer to those aspects of a job that require sustained physical and/or psychological effort and are assumed to be associated with a variety of physiological and/or psychological costs. In contrast, job resources help employees to achieve work-related goals, thus helping to balance the costs associated with job demands and to stimulating personal development. Based on the job demandsresources model, Schaufeli, Bakker et al. (2009) tested the relations between job demands (work overload, mental demands, emotional demands) and resources (social support from colleagues, supervisory coaching, opportunities to learn), and workaholism profiles. Their results showed that higher levels of job demands and lower levels of job resources predicted a higher likelihood of membership into the HC-HE profile. Similarly, Kravina et al. (2010) showed that higher levels of time pressure were associated with a higher likelihood of membership into the HC-HE profile. Also based on the job demands-resources model, Molino, Bakker, and Ghislieri (2016) recently examined the determinants of workaholism. Results revealed that job demands (i.e., workload, cognitive demands, emotional demands, and customer-related social stressors) were positively related to workaholism. In addition, job resources (job security and opportunities for development) buffered the relations between job demands and workaholism. In sum, past studies showed that job demands and resources were significant determinants of workaholism. In the present research, we also examine the role of various job demands and resources in the prediction of the likelihood of membership into workaholism profiles, and extend these prior investigations by considering a more extensive set of indicators of job demands (emotional dissonance in Study 1, role ambiguity in Study 2) and resources (psychosocial 
safety climate in Study 1, independence in Study 2).

Scott, Moore, and Miceli (1997) also suggested that some traits might be involved in the emergence of workaholism. Many others have similarly considered that workaholism may be influenced by personal characteristics (for a meta-analysis, see Clark et al., 2016) such as self-esteem (Ng et al., 2007) and perfectionism (Clark, Lelchook, \& Taylor, 2010). More generally, dispositional traits are known to play a major role in the emergence of addictions (e.g., Eysenck, 1997). Still, irrespective of the fact that workaholism represents a form of addiction to work (Schaufeli, Shimazu, \& Taris, 2009; Spence \& Robbins, 1992), very little attention has been paid to the effects of perfectionism on working compulsively and excessively. Thus, to increase our understanding of the role of individual characteristics, we also examine the links between self-oriented and socially prescribed perfectionism and the likelihood of membership into the various profiles in Study 2.

\section{Study 1: Emotional Dissonance and Perceptions of the Psychosocial Safety Climate}

Emotional dissonance reflects a discrepancy between the emotions one feels and the emotions one is required to display (Holman, Chissick, \& Totterdell, 2002). Emotional dissonance is experienced as a role conflict, leading to an unpleasant state of tension due to the inability to display authentic feelings (Hülsheger \& Schewe, 2011). Emotional dissonance is linked to employees' feelings that they have not functioned optimally or in accordance with their values, and presents a known association with employees' tendencies to ruminate about their work and with their levels of working compulsively (Sonnentag \& Bayer, 2005). Emotional dissonance is also an important form of job demand (Zapf, 2002), because it requires effortful regulatory processes (Baumeister, Bratslavsky, Muraven, \& Tice, 1998) likely to disrupt workers' concentration on their tasks, and increase their feelings of work overload. Emotional dissonance may thus directly increase the time spent at work as employees tend to catch up on what they perceive to be an unreasonable workload, thus leading to working excessively (Zohar, Tzischinski, \& Epstein, 2003). Although no research has yet analyzed the association between emotional dissonance and workaholism, Molino et al. (2016) showed that emotional demands were positively linked to workaholism. In line with these results, we hypothesized that emotional dissonance would predict a greater likelihood of membership in the HC-HE profile.

Psychosocial safety climate is defined as "policies, practices, and procedures for the protection of worker psychological health and safety" (Dollard \& Bakker, 2010, p. 580). Psychosocial safety climate stems emerges when organizations support stress prevention through involvement and commitment, and clearly communicate that employee psychological health and safety is as important as productivity (Hall, Dollard, \& Coward, 2010). Recent research has shown that psychosocial safety climate was negatively correlated with job demands, such as work pressure (Bailey, Dollard, McLinton, \& Richards, 2015; Law, Dollard, Tuckey, \& Dormann, 2011). This result suggest that organizations with high psychosocial safety climate might implement more efficient built-in workload management procedures, thus possibly helping to reduce workaholism (Schaufeli, Bakker et al., 2009). We thus hypothesized that perceptions of the psychosocial safety climate would be associated with a higher likelihood of membership in the LC-LE profile.

\section{Study 2: Job Demands and Resources, and Perfectionism}

In Study 1, we considered the role of one type of job demand (emotional dissonance) and resource (psychosocial safety climate) in the prediction of workaholism profiles. In Study 2, we extend this investigation by considering a more extensive set of indicators of job demands (mental and emotional load, role ambiguity) and resources (support from colleagues, hierarchical support, independence). In line with aforementioned results (e.g., Kravina et al., 2010; Molino et al., 2016; Schaufeli, Bakker et al., 2009), we hypothesized that job demands would predict a higher likelihood of membership in the HC-HE profile. Arguably, the more important job demands are, the more workers may be tempted to invest efforts and energy to meet these demands, possibly leading them to work excessively (Schaufeli, Taris, \& van Rhenen, 2008). Important job demands may also generate anxiety regarding one's ability to meet them, leading employees to spend more time ruminating about work, possibly leading them to work compulsively (Huyghebaert et al., 2016).

According to the conservation of resources theory, support from colleagues, hierarchical support, and independence are powerful resources to help maintain workers' wellbeing (Hobfoll, 1989) and their ability to manage job demands effectively (Spurk, Hirschi, \& Kauffeld, 2016). Employees who feel supported by their supervisor and colleagues may not come to rely on destructive forms of work overinvestment compared to those who feel more isolated at work (Spurk et al., 2016). Moreover, 
supervisor support have been found to be more frequently associated with a work environment where employees are not pushed to work extra hours, possibly leading to a reduced risk of workaholism (Mazzetti, Schaufeli, Guglielmi, \& Depolo, 2016). Finally, workers who feel sufficiently independent at work may dispose of a greater level of latitude to deal with their job demands within regular work schedules without feeling compelled to go overboard (Molino et al., 2016). Independence provides workers with opportunities to use their strengths without feeling that their personal resources are challenged or drained, or that they need to spend a great deal of time at work or to obsess about it to avoid losing these resources. We thus hypothesized that job resources would predict a higher likelihood of membership into the LC-LE profile (Schaufeli, Bakker et al., 2009).

Study 2 also focuses on the relations between self-oriented and socially prescribed perfectionism and the likelihood of membership into the various profiles. Self-oriented perfectionism is an internal drive to uphold exceedingly high personal standards and to criticize oneself harshly. Socially prescribed perfectionism comprises beliefs that others have high standards for oneself that must be met to achieve social acceptance (Hewitt \& Flett, 1991). Because perfectionists are driven by strong strivings for perfection, it would be logical to assume that self-oriented and socially prescribed perfectionism would foster these two workaholism components. This link is supported by evidence showing that global perfectionism was associated with higher levels of workaholism (Clark et al., 2016). Taris, van Beek, and Schaufeli (2010) further showed that the effect of socially prescribed perfectionism on global workaholism was stronger than that of self-oriented perfectionism. These results suggest that self-oriented and socially prescribed perfectionism should be important in the prediction of the likelihood of membership into the HC-HE profile. However, in line with Taris et al. (2010) and because socially prescribed perfectionism appears more detrimental than self-oriented perfectionism (Flett, Hewitt, \& Heisel, 2014), we leave as an open research question whether the two forms of perfectionism would differentially relate to the workaholism profiles.

\section{Outcomes of Workaholism Profiles}

To support a substantive interpretation of latent profiles as meaningful and relevant, it is critical to demonstrate that they relate to key outcomes and that they can be reliably replicated across samples (Marsh et al., 2009; Meyer \& Morin, 2016; Morin \& Wang, 2016). The research was specifically designed to address this issue, allowing for a direct test of whether the profiles, as well as their relations with outcomes and correlates, would replicate across samples. We now turn our attention to the outcomes, which were selected to be both complementary and similar across studies. Specifically, attitudinal and health outcomes were assessed in the present series of studies (i.e., work-family conflict, emotional exhaustion, perceived stress, turnover intentions, psychological detachment, job satisfaction, and perceived health in Study 1, as well as work-family conflict, emotional exhaustion, perceived health, and life satisfaction in Study 2). First, we studied the effects of workaholism profiles on various work outcomes previously documented to be associated with workaholism (e.g., emotional exhaustion) across a variety of cultural samples (e.g., Dutch: Schaufeli, Bakker et al., 2009; Italian: Kravina et al., 2010; Spanish: Salanova et al., 2016). Second, we also considered outcomes already found to be related to workaholism, but only in the context of past variable-centered research in order to see whether these results would generalize to but person-centered studies (e.g., work-family conflict). Third and finally, to complement prior research, we considered three potential outcomes of workaholism profiles not assessed in past studies (i.e., turnover intentions, psychological detachment, and life satisfaction).

Prior research has documented associations between workaholism profiles and work outcomes. Schaufeli, Bakker et al. (2009) showed that the HC-HE profile reported the highest levels of burnout and presenteeism, and the lowest levels of recovery, happiness, and performance. In contrast, the LCLE profile reported the lowest levels of burnout and presenteeism, and the highest levels of recovery, happiness, and performance. In addition, their results also showed that the HC-LE and LC-HE profiles did not differ in terms of recovery, happiness, presenteeism, and performance. Kravina et al. (2010) found that the HC-HE profile presented the highest levels of psychological strain and emotional exhaustion, while the HC-LE and LC-HE profiles did not differ on work satisfaction, emotional instability, and compliance. Salanova et al. (2016) showed that the HC-HE profile had lower sleep quantity and quality, as well as greater levels of alcohol use, and risk of cardiovascular difficulties. These relations may be explained by the conservation of resources theory (Hobfoll, 1989). Workaholics spend excessive amounts of time and energy on their work, leading to a state of extreme 
resource depletion, and leaving them with fewer resources to allocated to non-work activities (such as the family). Yet, when resources are threatened, lost, or not compensated, negative outcomes ensue (Hobfoll, 1989). Workers characterized by a HC-HE profile may thus display higher levels of ill-being and work-family conflict, and lower levels of satisfaction and performance.

Overall, these studies showed that the HC-HE profile was associated with the least adaptive outcomes, followed by the HC-LE and LC-HE profiles which are generally indistinguishable from one another, and finally by the LC-LE profile. We can thus expect attitudinal and health outcomes (i.e., Study 1: work-family conflict, emotional exhaustion, perceived stress, turnover intentions, psychological detachment, job satisfaction, and perceived health; Study 2: work-family conflict, emotional exhaustion, perceived health, and life satisfaction) to be differentially related to workaholism profiles. Based on prior research, we expect the HC-HE profile to be associated with the worst outcomes (Kravina et al., 2010; Salanova et al., 2016; Schaufeli, Bakker et al., 2009).

\section{Correlates of Workaholism Profiles}

Ryan and Deci's (2000) self-determination theory (SDT) clearly posits the role of work motivation in the prediction of workaholism (Stoeber, Davis, \& Townley, 2013; van Beek, Taris, \& Schaufeli, 2011). SDT distinguishes different types of motivation according to the degree to which workers embark in work-related behaviors for reasons that are autonomously-driven or controlled by internal or external pressures (Gagné \& Deci, 2005). Controlled motivation is seen as emerging from the thwarting of the basic psychological needs for autonomy (i.e., need to feel volitional and responsible), competence (i.e., need to feel efficient when interacting with others and to have opportunities to express one's abilities), and relatedness (i.e., need to feel socially secure and supported). Autonomous motivation is purported to emerge from the satisfaction of these three psychological needs (Ryan \& Deci, 2000). In this research, we focus on psychological need thwarting, both for practical reasons of testing time (i.e., we did not assess psychological need satisfaction to keep the length of the questionnaire manageable), but also because prior studies have shown that controlled motivation is more strongly correlated to workaholism than autonomous motivation (van Beek, Hu, Schaufeli, Taris, \& Schreurs, 2012; Van den Broeck et al., 2011). In line with these considerations, we expect levels of need thwarting to be the highest in the HC-HE profile. Indeed, when the need of competence is thwarted, feelings of self-worth are low, possibly leading workers to increase their job involvement in order to prove themselves (Spence \& Robbins, 1992). When workers feel oppressed (autonomy need thwarting), they may similarly increase their job involvement to better meet external demands (Ryan \& Deci, 2000). When employees feel despised (relatedness need thwarting), their workload may increase as they cannot rely on others' support to cope with job requirements. These considerations suggest that need thwarting may be a predictor of workaholism (Schaufeli, Bakker et al., 2009).

Still, research also suggests that need thwarting may also represent an outcome of workaholism, leading to our decision to position need thwarting as a correlate of workaholism profiles. Indeed, prior studies found high levels of workaholism to be linked to a lack of psychological detachment from work (Huyghebaert et al., 2016). This inability to cognitively disconnect from work impedes employees' recovery process (Sonnentag \& Fritz, 2007). On the one hand, when working excessively, workers consume their resources and have insufficient opportunities to recover from these efforts (Sonnentag \& Bayer, 2005). On the other hand, when working compulsively, workaholics are not able to psychologically disengage from work at home and more likely to become anxious and ruminate about work (van Beek et al., 2011). As a result, employees who do not psychologically detach from work come back to work in a physical and affective state that impedes their performance (Sonnentag \& Fritz, 2007), possibly leading them to develop a sense of worthlessness (competence need thwarting). Workaholics also generally feel a lack of control over their work (Ng et al., 2007), which they try to compensate by their over-involvement. Similar to obsessive work passion, workaholism results from the controlled internalization of work into one's identity (Vallerand et al., 2003). As a result, workaholics feel compelled to engage in work, leading to a reduced sense of volition (autonomy need thwarting). Finally, workaholics generally refuse to delegate work or to seek help, and fail to pay attention to others (Schaufeli et al., 2008). Such behaviors are likely to lead to a sense of social isolation or disconnection from others (relatedness need thwarting).

\section{The Present Research}

The present research examines how working compulsively and excessively combine within different subgroups of workers. In two studies based on independent samples, we also examine the 
links between the workaholism profiles and the thwarting of psychological needs for autonomy, competence, and relatedness represented as correlates. This research considers the role of emotional dissonance and psychosocial safety climate (Study 1) as well as self-oriented and socially prescribed perfectionism, and job demands and resources (Study 2), in the prediction of workers' likelihood of membership into workaholism profiles. Finally, to better document the construct validity and practical relevance of the identified profiles, we assess how they relate to a variety of attitudinal and health outcomes including work-family conflict, emotional exhaustion, perceived stress, turnover intentions, psychological detachment, job satisfaction, and perceived health in Study 1, as well as work-family conflict, emotional exhaustion, perceived health, and life satisfaction in Study 2.

\section{Method}

\section{Study 1}

Participants and Procedure. Undergraduate students collected the data related to this project. They distributed a paper-based questionnaire to a convenience sample of 465 workers (182 men; 283 women) from various organizations (e.g., public hospitals, industries, sales and services) located in France. In each organization, participants received a survey packet including the questionnaire, a cover letter explaining the study's purposes, and a consent form stressing that participation was anonymous and voluntary. Questionnaires required approximately 20 minutes to complete. Completed questionnaires were returned to the undergraduate students. No incentive was offered to take part in the study. This sample included 113 participants employed in the public sector $(24.3 \%)$ and 352 employed in the private sector (75.7\%). Respondents were aged between 18 and 62 years $(M=38.49$, $S D=13.07)$, had an average organizational tenure of 11.05 years $(S D=10.97)$, and an average tenure in the current position of 6.93 years $(S D=7.51)$. A total of 368 participants were full-time workers (79.1\%), whereas 380 participants were permanent workers $(81.7 \%)$ and 85 were temporary workers (18.3\%). Sixteen participants $(3.4 \%)$ had no diploma, 117 had a vocational training certificate (25.2\%), 146 had a high school diploma (31.4\%), and 186 had a university diploma (40.0\%).

\section{Measures.}

Workaholism. Working compulsively (5 items, $\alpha=.76$; e.g., "I find myself continuing to work after my coworkers have called it quits") and excessively (5 items, $\alpha=.75$; e.g., "I feel that there is something inside me that drives me to work hard") were measured using the French version (Sandrin \& Gillet, 2016) of the Dutch Workaholism Scale (Schaufeli, Shimazu, \& Taris, 2009). Items were rated on a 7-point scale ranging from 1 (never) to 7 (always).

Need thwarting (correlate). Need thwarting was assessed with the 9-item Psychological Need Thwarting at Work Scale (Gillet, Fouquereau, Lequeurre, Bigot, \& Mokounkolo, 2012). Three items each assessed the needs for competence $(\alpha=.80$; e.g., "It happens that I hear things that make me feel incompetent"), autonomy ( $\alpha=.75$; e.g., "I feel forced to behave in a certain way"), and relatedness ( $\alpha$ $=.81$; e.g., "I think other people hate me"). Items were rated on a 7-point scale (1- strongly disagree to 7- strongly agree).

Psychosocial safety climate (predictor). The 12-item Psychosocial Safety Climate scale (Hall et al., 2010) was used to assess four interrelated facets (3 items each): (1) managerial commitment (e.g., "Senior management considers employee psychological health to be as important as productivity"), (2) managerial priority (e.g., "Senior management clearly considers the psychological health of employees to be of great importance"), (3) organizational communication (e.g., "There is good communication here about psychological safety issues which affect me"), and (4) organizational participation (e.g., "Employees are encouraged to become involved in psychological safety and health matters"). These items were rated on a 5-point scale (1- strongly disagree to 5- strongly agree), and used to assess a single global construct ( $\alpha=.94$; Bailey, Dollard, \& Richards, 2015).

Emotional dissonance (predictor). Emotional dissonance was assessed with five items $(\alpha=.86$; e.g., "Having to show certain feelings that do not correspond with the way I feel at that moment") from the Frankfurt Emotion Work Scale (Zapf, Vogt, Seifert, Mertini, \& Isic, 1999) rated on a 5-point scale ranging from 1 (never) to 5 (always).

Work-family conflict (outcome). Work-family conflict was measured with a 3-item subscale $(\alpha=$ .89; e.g., "How often does it happen that your work schedule makes it difficult for you to fulfill your domestic obligations?") from the Survey Work Home Interaction Nijmegen (Demerouti, Bakker, \& Bulters, 2004). Items were rated on a 7-point scale (1- totally disagree to 7-totally agree).

Emotional exhaustion (outcome). Emotional exhaustion was assessed with a 5-item version $(\alpha=$ 
.86; e.g., "I feel emotionally drained by my work") of the Maslach Burnout Inventory-General Survey (Schaufeli, Leiter, Maslach, \& Jackson, 1996). All items were rated on a 1 (strongly disagree) to 5 (strongly agree) response scale.

Perceived stress (outcome). Perceived stress was assessed with the 4-item $(\alpha=.72$; e.g., "How often have you felt that you were unable to control the important things in your life?") version of the Perceived Stress Scale (Cohen, Kamarck, \& Mermelstein, 1983). Items were rated referring to the last month on a 5-point response scale (1- never to 5-always).

Turnover intentions (outcome). Turnover intentions were assessed with 3 items $(\alpha=.90$; e.g., "I often think about quitting this organization") developed by Bentein, Vandenberghe, Vandenberg, and Stinglhamber (2005) and rated on a 5-point response scale (1- strongly disagree to 5- strongly agree).

Psychological detachment (outcome). Psychological detachment was assessed with a scale developed by Sonnentag and Fritz (2007). Following a common stem (i.e., "In the evening, after work, and when I am on a weekend/vacation..."), four items ( $\alpha=.91$; e.g." "I forget about work") were rated on a 5 -point scale ranging from 1 (totally disagree) to 5 (totally agree).

Job satisfaction (outcome). Job satisfaction was assessed with three items $(\alpha=.76$; e.g., "I am satisfied with my job") of the Michigan Organizational Assessment Questionnaire (Cammann, Fichman, Jenkins, \& Klesh, 1983), rated on a 5-point scale (1- strongly disagree to 5- strongly agree).

Perceived health (outcome). Perceived health was assessed with four items $(\alpha=.82)$ based on the Medical Outcome Study (Stewart \& Ware, 1992). Participants were asked to answer the following questions: "In general, would you say your health is excellent, very good, good, fair, or poor?" (from 1- poor to 5- excellent), "To what extent do you have any particular health problems?" (from 1- no extent to 5- a very great extent), "Thinking about the past 2 months, how much of the time has your health kept you from doing the kind of things other people your age do?" (from 1- none of the time to 5- all of the time), and "To what extent do you feel healthy enough to carry out things that you would like to do?" (from 1-no extent to 5- a very great extent). The scoring of the second and third items was reversed so that a higher score represents better health.

Analyses

Preliminary Analyses. The psychometric properties of all measures were verified through preliminary factor analyses reported in the online supplements. These preliminary analyses were used to generate factor scores (estimated in standardized units with $M=0$ and $S D=1$ ), which are the variables used for the main analyses (for details on the advantages of factor scores, see Meyer \& Morin, 2016; Morin, Meyer, Creusier, \& Biétry, 2016). Factor scores do not explicitly control for measurement errors the way latent variables do, but provide a partial control for measurement errors by giving more weight to items presenting lower residuals (Skrondal \& Laake, 2001), and preserve the underlying nature of the measurement model better than scale scores (Morin, Meyer et al., 2016). Correlations for all of these factor scores, as well as their estimates of composite reliability obtained using McDonald (1970) omega ( $\omega=.589$ to $.958 ; M=.853)$, are reported in Table S5 of the online supplements. The fact that some estimates of composite reliability appear suboptimal reinforces the importance of adopting a method providing some level of control for measurement errors.

Latent Profile Analyses (LPA). LPA including one to eight latent profiles were estimated using Mplus 7.4 (Muthén \& Muthén, 2016) robust maximum likelihood estimator (MLR). To avoid converging on a suboptimal local maximum, all LPA were conducted using 5000 random sets of start values and 1000 iterations, with the 200 best solutions retained for final stage optimization (Hipp \& Bauer, 2006). In all LPA, the means and variances of the workaholism factor scores were freely estimated (Diallo, Morin \& Lu, 2016; Morin, Maïano et al., 2011). The procedure used to select the optimal number of profiles is disclosed in the online supplements.

Correlates, Predictors, and Outcomes. Following Meyer and Morin (2016; also see Morin, 2016), the associations between the latent profiles and the covariates were tested using methods appropriate to their status as predictors, correlates, or outcomes. Multinomial logistic regressions were conducted to test the relations between the predictors and the likelihood of membership into the various profiles. In multinomial logistic regressions each predictor is associated with $k-1$ ( $k=$ number of profiles) regression coefficients related to the comparison of each profile to all other profiles. These regression coefficients represent the effects of the predictors on the log-odds of the outcome (i.e., the pairwise probability of membership in one profile versus another in logarithmic units) for a one-unit increase in the predictor. Odds ratios (OR) are also be reported and reflect changes in the likelihood of 
membership in a target profile versus a comparison profile for each unit increase in the predictor. Correlates levels were contrasted using a Mplus AUXILIARY (e) function, which tests the equality of means across profiles through a Wald test based on pseudo-class draws (Asparouhov \& Muthén, 2007), without assuming any directionality of associations (Meyer \& Morin, 2016; Morin, 2016). Outcomes levels were contrasted using a model-based approach proposed by Lanza, Tan, and Bray (2013) and implemented through the Auxiliary (DCON) function (Asparouhov \& Muthén, 2014).

\section{Results}

Latent Profiles. The results revealed a 4-profile solution, which is graphically depicted in Figure 1a (detailed parameter estimates are reported in Table S8 of the online supplements). All four profiles mainly differ on the global level of workaholism that characterizes them, rather than showing clear qualitative differences based on specific dimensions of workaholism. Thus, Profile 1 describes $16.17 \%$ of the employees presenting a very low level of workaholism, whereas Profile 2 describes a smaller proportion $(3.43 \%)$ of the employees presenting a very high level of workaholism. The remaining profiles are larger, and less extreme, respectively characterizing employees presenting moderately high $(39.38 \%)$, or moderately low (41.02\%), levels of workaholism.

Predictors of Profile Membership. Predictors were added to this final 4-profile model. The results from this multinomial logistic regression are reported in the top section of Table 1 . These results show that participants' levels of emotional dissonance provide a well-differentiated pattern of association with the profiles, being associated with a higher likelihood of membership in the Very High (2), Moderately High (3), and Moderately Low (4) profiles relative to the Very Low (1) profile, as well as into the Very High (2) and Moderately High (3) profiles relative to the Moderately Low (4) profile. However, emotional dissonance did not differentially predict membership into the Very High (2) relative to the Moderately High (3) profiles. In contrast, participants' perceptions of their workplace psychosocial safety climate showed no significant association with profile membership.

Correlates of Profile Membership. The within-profile means of each correlate, together with their 95\% confidence intervals are reported in the top section of Table 2. Levels of need thwarting tended to be the highest in the Very High (2) and Moderately High (3) profiles, which were indistinguishable from one another, followed by the Moderately Low (4) and then by the Very Low (1) profiles, which could be differentiated on their levels of autonomy and competence (but not relatedness) need thwarting. Relatedness need thwarting showed the fewest differences, being only significantly higher in the Moderately High (3) relative to the Very Low (1) profile.

Outcomes of Profile Membership. The within-profile means of each outcome, together with their 95\% confidence intervals are reported in the bottom section of Table 2. These results were very consistent across outcomes, and showed that the most desirable outcomes levels (lower levels of workfamily conflict, emotional exhaustion, perceived stress, and turnover intentions, or higher levels of psychological detachment, job satisfaction, and perceived health) tended to be associated with the Very Low (1) profile, followed by the Moderately Low (4) profile, then by the Moderately High (3) profile, and finally by the Very High (2) profile, with most comparisons being statistically significant. Among the very few exceptions, levels of job satisfaction and perceived health were indistinguishable between the Very Low (1) and Moderately Low (4) profiles, and levels of perceived health were indistinguishable between the Very High (2) and Moderately High (3) profiles.

\section{Method}

\section{Study 2}

Participants and Procedure. This study relied on data collection procedures identical to those used in Study 1. In this study, a questionnaire was completed by a sample of 780 workers (307 men; 473 women) from various organizations located in France and independent from the one used in Study 1. This sample included 197 participants employed in the public sector $(25.3 \%)$ and 583 employed in the private sector $(74.7 \%)$. Respondents were aged between 18 and 64 years $(M=37.03, S D=10.67)$, had an average organizational tenure of 8.76 years $(S D=8.67)$, and an average tenure in the current position of 5.34 years $(S D=5.96)$. A total of 691 participants were full-time workers $(88.6 \%)$, whereas 677 participants were permanent workers $(86.8 \%)$ and 103 were temporary workers $(13.2 \%)$. Fourteen participants (1.8\%) had no diploma, 123 had a vocational training certificate $(15.8 \%), 152$ had a high school diploma (19.5\%), and 491 had a university diploma (62.9\%).

Measures. Workaholism, need thwarting (correlate), emotional exhaustion, perceived health, and work-family conflict (outcomes) were assessed as in Study 1. 
Perfectionism (predictor). A 10-item version of the Multidimensional Perfectionism Scale (Gaudreau \& Verner-Filion, 2012; Hewitt \& Flett, 1991) was used to assess self-oriented (5 items, $\alpha=$ .85 ; e.g., "I do whatever is possible to be as perfect as I can") and socially prescribed ( 5 items, $\alpha=.80$; e.g., "I feel that people are demanding too much of me") perfectionism. These items were rated on a response scale ranging from 1 (strongly disagree) to 7 (strongly agree).

Job demands and resources (predictors). Mental load ( 4 items, $\alpha=.84$; e.g., "Do you have to give continuous attention to your work?"), emotional load ( 4 items, $\alpha=.75$; e.g., "Does your work put you in emotionally upsetting situations?"), role ambiguity (4 items, $\alpha=.71$; e.g., "Do you know exactly for what you are responsible and which areas are not your responsibility?", reversed item), support from colleagues ( 4 items, $\alpha=.85$; e.g., "Can you count on your colleagues when you encounter difficulties in your work?"), hierarchical support (4 items, $\alpha=.90$; e.g., "Is there a good atmosphere between you and your supervisor?"), and independence (4 items, $\alpha=.81$; e.g., "Can you decide the order in which you carry out your work on your own?") were measured with six subscales from a comprehensive measure developed and validated by Lequeurre, Gillet, Ragot, and Fouquereau (2013). Responses were provided on a 7-point response scale ranging from 1 (never) to 7 (always).

Life satisfaction (outcome). Life satisfaction was assessed with the Satisfaction with Life Scale (Diener, Emmons, Larsen, \& Griffin, 1985). Each of the five items $(\alpha=.88$; e.g., "I am satisfied with my life") were rated on a 7-point scale ranging from 1 (strongly disagree) to 7 (strongly agree).

Analyses. The current study relied on an analytical strategy that parallels that used in Study 1. Correlations among all variables and composite reliability coefficients $(\omega=.605$ to $.930 ; M=.836)$ are reported in Table S6 of the online supplements. Details on the preliminary analyses used to generate factor scores and select the optimal number of profiles are reported in the online supplements.

\section{Results}

Latent Profiles. The results revealed a 4-profile solution, which is graphically depicted in Figure $1 \mathrm{~b}$ (detailed parameter estimates are reported in Table S9 of the online supplements). More precisely, they showed profiles that were almost identical, both in shape and in size, to those identified in Study 1 and characterizing employees presenting Very Low (Profile 1: 11.04\%), Very High (Profile 2: 11.34\%), Moderately High (Profile 3: 39.07\%), and Moderately Low (Profile 4: 38.54\%) levels of workaholism.

Predictors of Profile Membership. Predictors were added to this 4-profile model. The results from this multinomial logistic regression are reported in the bottom section of Table 1. Surprisingly, very few of these predictions were significant, supporting the idea that the identification of meaningful predictors of workaholism is seldom a simple matter. These result show that, while participants' levels of self-oriented perfectionism show no significant association with profile membership, their levels of socially prescribed perfectionism are associated with a higher likelihood of membership in the Very High (2) profile relative to both the Moderately Low (4) and Very Low (1) profiles. Interestingly, the results also show that, whereas participants' levels of mental load show no significant association with profile membership, their levels of emotional load also predict a higher likelihood of membership in the Very High (2) and Moderately High (3) profiles relative to the Very Low (1) profile. Participants' levels of support from their colleagues predict a higher likelihood of membership into the Moderately Low (4) profile relative to the Moderately High (3) profile, whereas their levels of hierarchical support predict a higher likelihood of membership into the Moderately High (3) profile relative to the Moderately Low (4) profile. Finally, participants' role ambiguity and independence are not associated with the likelihood of membership into any of the profiles.

Correlates of Profile Membership. The within-profile means of each correlate, together with their 95\% confidence intervals are reported in the top section of Table 2. These results replicate those of Study 1 in terms of the ordering of need thwarting levels between the profiles, with the exception that all comparisons proved to be significant when estimated in this larger sample. Participants' levels of need thwarting tended to be the highest in the Very High (2) profile, followed by the Moderately High (3) profile, then by the Moderately Low (4) profile, and finally by the Very Low (1) profile.

Outcomes of Profile Membership. The within-profile means of each outcome, together with their $95 \%$ confidence intervals are reported in the bottom section of Table 2. These results once again replicate those from Study 1, showing that the most desirable outcomes levels (lower levels of workfamily conflict and emotional exhaustion, or higher levels of life satisfaction and perceived health) were associated with the Very Low (1) profile, followed by the Moderately Low (4) profile, then by 
the Moderately High (3) profile, and finally by the Very High (2) profile. Among the very few exceptions, we note that levels of life satisfaction and perceived health were indistinguishable between Very High (2) and Moderately High (3) profiles, and levels of perceived health were also indistinguishable between the Very Low (1) and Moderately Low (4) profiles.

\section{General Discussion}

In the present series of studies, we relied on a multidimensional conceptualization of workaholism, implying that workaholism is constituted by the combination of working excessively and working compulsively (Schaufeli, Shimazu, \& Taris, 2009). According to Schaufeli, Bakker et al. (2009) and in line with past person-centered studies (Kravina et al., 2010; Salanova et al., 2016), it follows that workaholism cannot be reduced to either of these two components. Many studies have shown that the two dimensions of workaholism are positively and moderately to strongly related (e.g., Huyghebaert et al., 2016), yet the added value of considering these two components, rather than a single combined score of workaholism, remained unknown. In addition, relatively little attention has been allocated to understanding the combined effects of the two components of workaholism, relative to the effects of displaying a single of these components among workers. In other words, it appeared critical to understand the true consequences of displaying high levels of both working excessively and working compulsively for workers and organizations. The reliance on a person-centered approach appeared to be particularly well-suited to these considerations, providing a way to assess how these two types of workaholism are combined among different profiles of employees, and the relative consequences of membership into these various profiles.

Our first purpose was to identify workaholism profiles based on the two facets of workaholism (working compulsively and excessively) proposed by Schaufeli, Shimazu, and Taris (2009). Our results revealed that four distinct profiles best represented the workaholism configurations among two independent samples of French workers. Two of these profiles met our expectations and results from prior studies (e.g., Kravina et al., 2010; Schaufeli, Bakker et al., 2009). Specifically, the Very High profile was characterized by high levels of working compulsively and excessively, while the Very Low profile was characterized by low levels of working compulsively and excessively. However, although prior studies also generally identified four profiles (Kravina et al., 2010; Salanova et al., 2016), two of the profiles identified here did not match prior results. Thus, the Moderately High and Moderately Low profiles were respectively characterized by moderately high and moderately low levels of working compulsively and excessively.

Prior variable-centered (Mazzetti et al., 2016; Sandrin \& Gillet, 2016) and cluster analytic (Schaufeli, Bakker et al., 2009) studies generally suggested that it might be important to distinguish the two facets of workaholism. For instance, Huyghebaert et al. (2016) showed that working excessively, but not working compulsively, positively predicted work-family conflict and lack of psychological detachment, suggesting that it is the behavioral component of workaholism that matters in predicting impaired functioning. Still, this previous result could also simply be a reflection of the high correlation observed between these two components. Indeed, our results argue against the addedvalue of distinguishing between the behavioral and cognitive facets of workaholism, rather suggesting that workaholism tends to be characterized by matching levels on those facets. The high correlation observed between the two subscales (.77 in Study 1, .82 in Study 2, .52 in Huyghebaert et al., 2016) is also in line with this conclusion. In addition, the fact that our results were fully replicated across two independent samples of employees recruited from a diversified set of organizations and industry sectors reinforces their generalizability.

The divergent person-centered results may also reflect methodological differences, such as: (a) the reliance on factor scores providing us with an improved control for measurement errors, and (b) the use of more flexible LPA which allowed us to relax the restrictive assumptions of cluster analyses. Indeed, in contrast to cluster analyses, LPA does not assume that the variance of the profile indicators is invariant across profiles. Furthermore, LPA allows all participants to have a probability of membership in all profiles based on their similarity with each prototypical latent profile. LPA also allows for the direct specification of alternative models that can be compared with fit statistics, allowing for the comparison of solutions including differing numbers of latent profiles based on a wide array of statistical indicators. Finally, because the profiles and all of the relations are estimated in a single step, the Type 1 errors are limited and the biases in the estimation of the links between covariates and the latent profiles are reduced (see Meyer \& Morin, 2016). Still, additional LPA 
research is needed to more extensively assess the generalizability of our findings.

\section{Predictors of Workaholism Profiles}

Little research has been conducted to identify the social characteristics that contribute to the development of workaholism profiles (e.g., Caesens et al., 2014), a limitation which we sought to address in the present research. Contrary to our expectations, participants' perceptions of their workplace psychosocial safety climate showed no significant association with profile membership. Study 2 also failed to identify associations between employees' levels of independence and profile membership, but showed that other job resources predicted profile membership, thus providing partial support to our hypotheses. In line with Caesens et al. (2014), we found that support from colleagues predicted a higher likelihood of membership into the Moderately Low relative to the Moderately High profile. In contrast, hierarchical support predicted a higher likelihood of membership into the Moderately High relative to the Moderately Low profile. These results are aligned with $\mathrm{Ng}$ and Sorensen's (2008), which showed that the effects of different sources of social support may sometimes be very dissimilar. Still, it is particularly noteworthy that neither source of social support differently predicted membership into the two extreme (Very High vs. Very Low) profiles. Our results thus suggest that job resources might only minimally limit workaholism, and suggest that caution is needed in the provision of hierarchical support, as this source of support tends to be associated with higher than average levels of workaholism (also see Mazzetti et al., 2016). Future research needs to more extensively look at positive workplace characteristics that might curb workaholism, and try to unpack the mechanisms underlying the positive relation between hierarchical support and workaholism.

In contrast, associations between job demands and profile membership provided stronger support to our hypotheses. These results supported our assertion that higher job demands may lead employees to invest energy to meet these demands and become anxious about their ability to do so, possibly leading to excessive and compulsive work (Schaufeli et al., 2008). In Study 1, participants' levels of emotional dissonance (a job demand; Zapf, 2002) provided a well-differentiated pattern of association with the profiles, being associated with a higher likelihood of membership in the Very High, Moderately High, and Moderately Low profiles relative to the Very Low profile, as well as in the Very High and Moderately High profiles relative to the Moderately Low profile. These results are aligned with our hypotheses, supporting the idea that emotional dissonance may: (a) impede the ability to psychologically detach from work, thus leading to working compulsively (Sonnentag \& Bayer, 2005), and (b) increase workers' feelings of workload, thus leading to working excessively (Zohar et al., 2003). To the best of our knowledge, this is the first study to demonstrate a significant association between emotional dissonance and workaholism.

Similarly, results from Study 2 also supported our expectations, showing that emotional load predicted a higher likelihood of membership in the Very High and Moderately High profiles relative to the Very Low profile. However, two of the three job demands assessed in Study 2 (mental load and role ambiguity) showed no significant association with profile membership, suggesting that only some types of job demands of an emotional (emotional dissonance and emotional load) rather than cognitive (mental load, role ambiguity) nature are associated with workaholism profiles. It appears for future research to look more carefully at the predictive role of other types of job demands (e.g., uncertainty about the future). Finally, Study 2 also revealed that participants' levels of self-oriented perfectionism showed no significant association with profile membership. However, they also showed that higher levels of socially prescribed perfectionism predicted an increased likelihood of membership in the Very High profile relative to both the Moderately Low and Very Low profiles. These results are in line with past studies showing that socially prescribed perfectionism appear particularly important in fostering workaholism (Taris et al., 2010). Indeed, high levels of socially prescribed perfectionism lead to a strong drive to excel out of a desire to demonstrate to others our ability to perform at work.

\section{Outcomes of Workaholism Profiles}

Our results showed that workaholism profiles presented well-differentiated associations with the various outcomes considered here. Specifically, the Very High profile was found to be associated with higher levels of work-family conflict, emotional exhaustion, perceived stress, and turnover intentions, and lower levels of psychological detachment, job satisfaction, life satisfaction, and perceived health, followed by the Moderately High profile, then by the Moderately Low profile, and finally by the Very Low profile. However, it is noteworthy that the Very Low and Moderately Low profiles did not differ from one another on job satisfaction and perceived health, while the Very High and Moderately High 
profiles did not differ from one another on life satisfaction and perceived health. Thus, these results show that the key determinant of satisfaction and perceived health seems to be the presence, or absence, of workaholism, rather than the degree of workaholism. The results are particularly interesting given that there has been a great deal of debate in the literature about the link between workaholism and these forms of satisfaction. More specifically, some researchers have conceptualized workaholics as lacking work enjoyment (Spence \& Robbins, 1992), while others claim that workaholics tend to enjoy work ( $\mathrm{Ng}$ et al., 2007). Contrary to this latter view, our results showed workaholism to be negatively related to satisfaction toward work and life in general.

Our results support the idea that undesirable outcomes tend to be associated with working compulsively and excessively (Schaufeli, Shimazu, \& Taris, 2009; van Beek et al., 2011), and are well aligned with prior research documenting the negative effects of workaholism on happiness, job satisfaction, and life satisfaction (Aziz \& Zickar, 2006; Bakker, Demerouti, Oerlemans, \& Sonnentag, 2013). When working excessively, workers devote a major amount of time and energy to their professional activities at the expense of their personal life and health. Moreover, when working compulsively, workers' obsession with work tends to be accompanied by persistent work-related ruminations. Thus, workaholics consume their resources and have insufficient opportunities to recover because they work long hours, and are unable to really rest when they finally stop working (Sonnentag \& Bayer, 2005). Workaholism is thus incompatible with psychological detachment and recovery, in turn leading to negative outcomes (Huyghebaert et al., 2016).

\section{Correlates of Workaholism Profiles}

Prior research could equally be used to support expectations of need thwarting as an outcome, or a predictor, of workaholism profiles, leading to our decision to treat it as a simple correlate (Meyer \& Morin, 2016). Indeed, when the needs of autonomy, competence, and relatedness are thwarted, workers are driven by an internal pressure to meet external demands, their feelings of self-worth are low and their workload may increase, possibly leading to workaholism (Schaufeli, Bakker et al., 2009). Moreover, workaholics feel compelled to engage in work, have insufficient opportunities to recover from these efforts, and often fail to pay attention to others. As a result, they experience high levels of autonomy, competence, and relatedness need thwarting (Schaufeli et al., 2008). Levels of need thwarting tended to be the highest in the Very High and Moderately High profiles (which differed from one another in Study 2, but not in Study 1), followed by the Moderately Low and then by the Very Low profiles, which could be differentiated from one another on their levels of autonomy, competence, and relatedness (but only in Study 2 for relatedness) need thwarting. This slight difference in results could possibly be related to the lower sample size of Study 1, which resulted in larger confidence intervals, making it harder to detect significant differences.

\section{Limitations and Directions for Future Research}

Limitations of the present research need to be acknowledged. First, we used self-report measures and such measures can be impacted by social desirability and self-report biases. Additional research should be conducted using objective turnover data as well as informant-reported measures of work performance. Second, we used of a cross-sectional design, which precludes interpretations regarding the directionality of the relations between predictors, correlates, outcomes, and profiles. Thus, we are unable to determine whether workaholism profiles influence employees' need satisfaction, or vice versa. Similarly, although our treatment of turnover intentions and ill/wellbeing as outcomes was based on theoretical considerations (Schaufeli, Bakker et al., 2009), our design did not allow us to rule out the possibility of reverse causality, reciprocal influence, or spurious associations. Future longitudinal research should devote more attention to the clear identification of the true directionality of the associations among predictors, correlates, outcomes, and profiles. It would also be important for future research to better consider the mechanisms involved in both the formation and consequences of the workaholism profiles. Furthermore, additional research could adopt a longitudinal design to address the joint issues of within-person and within-sample profile stability (Kam, Morin, Meyer, \& Topolnytsky, 2016). More importantly, future longitudinal research is needed to address explanations for, and limits to, profile stability while considering longer time periods and possible changes in the personal and professional lives of the employees to more carefully locate determinants of these changes. Third, we only considered self-oriented and socially prescribed perfectionism. It would be interesting for future research to also examine "other-oriented" perfectionism (Hewitt \& Flett, 1991). More generally, future research is needed to consider a more diversified set of determinants of 
workaholism profiles, such as perceived organizational support and career barriers (Caesens et al., 2014; Spurk et al., 2016). Finally, we relied on samples of French workers. Future research should examine whether the same profiles emerge in different countries and cultures.

\section{Practical Implications}

In practice, our results suggest that managers and practitioners should be particularly attentive to workers displaying high levels of working compulsively and excessively as these individuals appear to be at risk for a variety of work difficulties, such as emotional exhaustion, lack of psychological detachment, and turnover intentions. Organizations should also avoid situations where emotional dissonance is high to help reduce employees' workaholism. Organizations need to understand that emotional dissonance comes as a psychological cost for the organization and acknowledge employees' emotional efforts through their human resource policies and practices. Among the available methods to help reduce emotional dissonance, mindfulness techniques may prove useful (Hülsheger, Alberts, Feinholdt, \& Lang, 2013). Moreover, organizations may train employees on how to communicate with coworkers, supervisors, customers, and shareholders (Kenworthy, Fay, Frame, \& Petree, 2014), given that appropriate communication skills tend to help to communicate emotions more appropriately, thus reducing emotional dissonance. When employees have no option but to display emotions irrespective of their felt emotions, organizations can also minimize the negative effect of emotional dissonance by fostering employees' perceptions of organizational support (Mishra \& Kumar, 2016). Finally, high levels of socially prescribed perfectionism were associated with an increased likelihood of membership into the Very High profile. Thus, reducing socially-prescribed perfectionism might help to reduce workaholism, in turn leading to more positive attitudinal, health, and behavioral outcomes (Childs \& Stoeber, 2012). Reducing this form of perfectionism might be achieved through therapy, training, and support, although changing one's personality is difficult. Organizations may also consider regular feedback and participative goal setting, which may help perfectionists to see that they are meeting objectives, thus limiting feelings of guilt (Hochwarter \& Byrne, 2010).

\section{References}

Asparouhov, T., \& Muthén, B. (2007). Wald test of mean equality for potential latent class predictors in mixture modeling. Technical Report. Los Angeles, CA: Muthén \& Muthén

Asparouhov, T., \& Muthén, B. (2014) Auxiliary variables in mixture modeling: Three-step approaches using Mplus. Structural Equation Modeling, 21, 329-341.

Aziz, S., \& Zickar, M. J. (2006). A cluster analysis investigation of workaholism as a syndrome. Journal of Occupational Health Psychology, 11, 52-62.

Bakker, A. B., \& Demerouti, E. (2007). The Job Demands-Resources model: State of the art. Journal of Managerial Psychology, 22, 309-328.

Bakker, A. B., Demerouti, E., \& Euwema, M. C. (2005). Job resources buffer the impact of job demands on burnout. Journal of Occupational Health Psychology, 10, 170-180.

Bakker, A. B., Demerouti, E., Oerlemans, W., \& Sonnentag, S. (2013). Workaholism and daily recovery. Journal of Organizational Behavior, 34, 87-107.

Bailey, T. S., Dollard, M. F., McLinton, S. S., \& Richards, P. A. M. (2015). Psychosocial safety climate, psychosocial and physical factors in the aetiology of musculoskeletal disorder symptoms and workplace injury compensation claims. Work \& Stress, 29, 190-211.

Bailey, T. S., Dollard, M. F., \& Richards, P. A. M. (2015). A national standard for psychosocial safety climate (PSC): PSC 41 as the benchmark for low risk of job strain and depressive symptoms. Journal of Occupational Health Psychology, 20, 15-26.

Baumeister, R. F., Bratslavsky, E., Muraven, M., \& Tice, D. M. (1998). Ego depletion: Is the active self a limited resource? Journal of Personality and Social Psychology, 74, 1252-1265.

Bentein, K., Vandenberg, R. J., Vandenberghe, C., \& Stinglhamber, F. (2005). The role of change in the relationship between commitment and turnover: A latent growth modeling approach. Journal of Applied Psychology, 90, 468-482.

Buelens, M., \& Poelmans, S. A. Y. (2004). Enriching the Spence and Robbins' typology of workaholism: Demographic, motivational and organizational correlates. Journal of Organizational Change Management, 17, 440-458.

Cammann, C., Fichman, M., Jenkins, G., \& Klesh, J. (1983). Michigan Organizational Assessment Questionnaire. In S. Seashore, E. Lawler, P. Mirvis, \& C. Cammann (Eds.), Assessing organizational change (pp. 71-138). New York: Wiley-Interscience. 
Caesens, G., Stinglhamber, F., \& Luypaert, G. (2014). The impact of work engagement and workaholism on well-being: The role of work-related social support. The Career Development International, 19, 813-835.

Childs, J. H., \& Stoeber, J. (2012). Do you want me to be perfect? Two longitudinal studies on socially prescribed perfectionism, stress and burnout in the workplace. Work \& Stress, 26, 347-364.

Clark, M., Lelchook, A. M., \& Taylor, M. L. (2010). Beyond the big five: How narcissism, perfectionism, and dispositional affect relate to workaholism. Personality and Individual Differences, 48, 786-791.

Clark, M., Michel, J., Zhdanova, L., Pui, S, \& Baltes, B. (2016). All work and no play? A meta-analytic examination of the correlates and outcomes of workaholism. Journal of Management, 42, 1836-1873.

Cohen, S., Kamarck, T., \& Mermelstein, R. (1983). A global measure of perceived stress. Journal of Health and Social Behavior, 24, 385-396.

Demerouti, E., Bakker, A. B., \& Bulters, A. J. (2004). The loss spiral of work pressure, work-home interference and exhaustion: Reciprocal relations in a three-wave study. Journal of Vocational Behavior, 64, 131-149.

Diallo, T. M. O, Morin, A. J. S., \& Lu, H. (2016). Impact of misspecifications of the latent variancecovariance and residual matrices on the class enumeration accuracy of growth mixture models. Structural Equation Modeling, 23, 507-531.

Diener, E., Emmons, R. A., Larsen, R. J., \& Griffin, S. (1985). The Satisfaction With Life Scale. Journal of Personality Assessment, 49, 71-76.

Dollard, M. F., \& Bakker, A. B. (2010). Psychosocial safety climate as a precursor to conducive work environments, psychological health problems, and employee engagement. Journal of Occupational and Organizational Psychology, 83, 579-599.

Eysenck, H. (1997). Addiction, personality, and motivation. Human Psychopharmacology, 12, 79-87.

Flett, G. L., Hewitt, P. L., \& Heisel, M. J. (2014). The destructiveness of perfectionism revisited: Implications for the assessment of suicide risk and the prevention of suicide. Review of General Psychology, 18, 156-172.

Gagné, M., \& Deci, E. L. (2005). Self-determination theory and work motivation. Journal of Organizational Behavior, 26, 331-362.

Gaudreau, P., \& Verner-Filion, J. (2012). Dispositional perfectionism and well-being: A test of the $2 \times$ 2 model of perfectionism in sports. Sport, Exercise, \& Performance Psychology, 1, 29-43.

Gillet, N., Fouquereau, E., Lequeurre, J., Bigot, L., \& Mokounkolo, R. (2012). Validation of a scale for measuring need thwarting at work. Psychologie du Travail et des Organisations, 18, 328-344.

Hall, G. B., Dollard, M. F., \& Coward, J. (2010). Psychosocial safety climate: Development of the PSC-12. International Journal of Stress Management, 17, 353-383.

Hewitt, P. L., \& Flett, G. L. (1991). Perfectionism in the self and social contexts: Conceptualization, assessment, and association with psychopathology. Journal of Personality and Social Psychology, 60, 456-470.

Hipp, J. R., \& Bauer, D. J. (2006). Local solutions in the estimation of growth mixture models. Psychological Methods, 11, 36-53.

Hobfoll, S. E. (1989). Conservation of resources: A new attempt at conceptualizing stress. American Psychologist, 44, 513-524.

Hochwarter, W. A., \& Byrne, Z. S. (2010). The interactive effects of chronic pain, guilt, and perfectionism on work outcomes. Journal of Applied Social Psychology, 40, 76-100.

Holman, D., Chissick, C., \& Totterdell, P. (2002). The effects of performance monitoring on emotional labor and well-being in call centers. Motivation \& Emotion, 26, 57-81.

Hülsheger, U. R., Alberts, H. J. E. M., Feinholdt, A., \& Lang, J. W. B. (2013). Benefits of mindfulness at work: The role of mindfulness in emotion regulation, emotional exhaustion, and job satisfaction. Journal of Applied Psychology, 98, 310-325.

Hülsheger, U. R., \& Schewe, A. F. (2011). On the costs and benefits of emotional labor: A metaanalysis of three decades of research. Journal of Occupational Health Psychology, 16, 361-389.

Huyghebaert, T., Fouquereau, E., Lahiani, F.-J., Beltou, N., Gimenes, G., \& Gillet, N. (2016). Examining the longitudinal effects of workload on ill-being through each dimension of workaholism. International Journal of Stress Management. Early view. doi: 10.1037/str0000055

Kam, C., Morin, A. J. S., Meyer, J. P., \& Topolnytsky, L. (2016). Are commitment profiles stable and 
predictable? A latent transition analysis. Journal of Management, 42, 1462-1490.

Kenworthy, J., Fay, C., Frame, M., \& Petree, R. (2014). A meta-analytic review of the relation between emotional dissonance and emotional exhaustion. Journal of Applied Social Psychology, 44, 94-105.

Kravina, L, Falco, A., Girardi, D., \& De Carlo, N. A. (2010). Workaholism among management and workers in an Italian cooperative enterprise. TPM-Testing, Psychometrics, Methodology in Applied Psychology, 17, 201-216.

Lanza S. T., Tan X., \& Bray B. C. (2013). Latent class analysis with distal outcomes: A flexible model-based approach. Structural Equation Modeling, 20, 1-26.

Law, R., Dollard, M. F., Tuckey, M. R., \& Dormann, C. (2011). Psychosocial safety climate as a lead indicator of workplace bullying and harassment, job resources, psychological health and employee engagement. Accident Analysis and Prevention, 43, 1782-1793.

Lequeurre, J., Gillet, N., Ragot, C., \& Fouquereau, E. (2013). Validation of a French questionnaire to measure job demands and resources. Revue Internationale de Psychologie Sociale, 26, 93-124.

Machlowitz, M. (1980). Workaholics: Living with them, working with them. New York: Simon \& Schuster.

Marsh, H. W., Lüdtke, O., Trautwein, U., \& Morin, A. J. S. (2009). Classical latent profile analysis of academic self-concept dimensions: Synergy of person- and variable-centered approaches to theoretical models of self-concept. Structural Equation Modeling, 16, 191-225.

Mazzetti, G., Schaufeli, W. B., Guglielmi, D., \& Depolo, M. (2016). Overwork climate scale: Psychometric properties and relationships with working hard. Journal of Managerial Psychology, 31, 880-896.

McDonald, R. (1970). Theoretical foundations of principal factor analysis, canonical factor analysis, and alpha factor analysis. British Journal of Mathematical \& Statistical Psychology, 23, 1-21.

Meyer, J. P., \& Morin, A. J. S. (2016). A person-centered approach to commitment research: Theory, research, and methodology. Journal of Organizational Behavior, 37, 584-612.

Mishra, S. K., \& Kumar, K. K. (2016). Minimizing the cost of emotional dissonance at work: A multisample analysis. Management Decision, 54, 778-795.

Molino, M., Bakker, A. B., \& Ghislieri, C. (2016). The role of workaholism in the job demandsresources model. Anxiety, Stress \& Coping: An International Journal, 29, 400-414.

Morin, A. J. S. (2016). Person-centered research strategies in commitment research. In J. P. Meyer (Ed.), The handbook of employee commitment (p. 490-508). Cheltenham, UK: Edward Elgar.

Morin, A. J. S., Maïano, C., Nagengast, B., Marsh, H. W., Morizot, J., \& Janosz, M. (2011). Growth mixture modeling of adolescents trajectories of anxiety: The impact of untested invariance assumptions on substantive interpretations. Structural Equation Modeling, 18, 613-648.

Morin, A. J. S., Meyer, J. P., Creusier, J., \& Biétry, F. (2016). Multiple-group analysis of similarity in latent profile solutions. Organizational Research Methods, 19, 231-254.

Morin, A. J. S., Morizot, J., Boudrias, J.-S., \& Madore, I., (2011). A multifoci person-centered perspective on workplace affective commitment: A latent profile/factor mixture analysis. Organizational Research Methods, 14, 58-90.

Morin, A. J. S., \& Wang, J. C. K. (2016). A gentle introduction to mixture modeling using physical fitness data. In N. Ntoumanis, \& N. Myers (Eds.), An introduction to intermediate and advanced statistical analyses for sport and exercise scientists (pp. 183-210). London, UK: Wiley.

Muthén, L. K., \& Muthén, B. (2016). Mplus user's guide. Los Angeles, CA: Muthén \& Muthén.

Ng, T. W. H., \& Sorensen, K. L. (2008). Toward a further understanding of the relationships between perceptions of support and work attitudes: A meta-analysis. Group \& Organization Management, 33, 243-268.

Ng, T. W. H., Sorensen, K. L., \& Feldman, D. C. (2007). Dimensions, antecedents, and consequences of workaholism. Journal of Organizational Behavior, 28, 111-136.

Oates, W. (1971). Confessions of a workaholic: The facts about work addiction. New York: World.

Ryan, R. M., \& Deci, E. L. (2000). Intrinsic and extrinsic motivations: Classic definitions and new directions. Contemporary Educational Psychology, 25, 54-67.

Salanova, M., Del Libano, M., Llorens, S., \& Schaufeli, W. B. (2014). Engaged, workaholic, burnedout or just 9-to-5? Toward a typology of employee well-being. Stress and Health, 30, 71-81.

Salanova, M., López-González, A. A., Llorens, S., del Líbano, M., Vicente-Herrero, M. T., \& TomásSalvá, M. (2016). Your work may be killing you! Workaholism, sleep problems and cardiovascular risk. Work \& Stress, 30, 228-242. 
Sandrin, E., \& Gillet, N. (2016). Validation of a French version of the Dutch Work Addiction Scale (DUWAS). Psychologie du Travail et des Organisations, 22, 147-159.

Schaufeli, W. B., Bakker, A. B., van der Heijden, F. M. M. A., \& Prins, J. T. (2009). Workaholism among medical residents: It is the combination of working excessively and working compulsively that counts. International Journal of Stress Management, 16, 249-272.

Schaufeli, W. B., Leiter, M. P., Maslach, C., \& Jackson, S. E. (1996). The Maslach Burnout Inventory-General Survey. In C. Maslach, S. E. Jackson, \& M. P. Leiter (Eds.), Maslach Burnout Inventory ( $3^{\text {rd }}$ ed., pp. 19-26). Palo Alto, CA: Consulting Psychologists Press.

Schaufeli, W. B., Shimazu, A., \& Taris, T. W. (2009). Being driven to work excessively hard: The evaluation of a two-factor measure of workaholism in the Netherlands and Japan. Cross-Cultural Research, 43, 320-348.

Schaufeli, W. B., Taris, T. W., \& van Rhenen, W. (2008). Workaholism, burnout, and work engagement: Three of a kind or three different kinds of employee well-being? Applied Psychology: An International Review, 57, 173-203.

Scott, K. S., Moore, K. S., \& Miceli, M. P. (1997). An exploration of the meaning and consequences of workaholism. Human Relations, 50, 287-314.

Skrondal, A., \& Laake, P. (2001). Regression among factor scores. Psychometrika, 66, 563-576.

Smith, M. M., Sherry, S. B., Rnic, K., Saklofske, D. H., Enns, M., \& Gralnick, T. (2016). Are perfectionism dimensions vulnerability for depressive symptoms after controlling for neuroticism? A meta-analysis of longitudinal studies. European Journal of Personality, 30, 201-212.

Sonnentag, S., \& Bayer, U.-V. (2005). Switching off mentally: Predictors and consequences of psychological detachment from work during off-job time. Journal of Occupational Health Psychology, 10, 393-414.

Sonnentag, S., \& Fritz, C. (2007). The Recovery Experience Questionnaire: Development and validation of a measure for assessing recuperation and unwinding from work. Journal of Occupational Health Psychology, 12, 204-221.

Spence, J., \& Robbins, A. (1992). Workaholism: Definition, measurement, and preliminary results. Journal of Personality Assessment, 58, 160-178.

Spurk, D., Hirschi, A., \& Kauffeld, S. (2016). A new perspective on the etiology of workaholism: Personal and contextual career-related antecedents. Journal of Career Assessment, 24, 747-764.

Stewart, A. L., \& Ware, J. E. (1992). Measuring functioning and well-being: The Medical Outcomes Study approach. Durham, NC: Duke University Press.

Stoeber, J., Davis, C. R., \& Townley, J. (2013). Perfectionism and workaholism in employees: The role of work motivation. Personality and Individual Differences, 55, 733-738.

Taris, T. W., van Beek, I., \& Schaufeli, W. B. (2010). Why do perfectionists have a higher burnout risk than others? A mediational analysis. Romanian Journal of Applied Psychology, 12, 1-7.

Vallerand, R. J., Blanchard, C., Mageau, G. A., Koestner, R., Ratelle, C., Léonard, M., Gagné, M., \& Marsolais, J. (2003). Les passions de l'âme: On obsessive and harmonious passion. Journal of Personality and Social Psychology, 85, 756-767.

van Beek, I., Hu, Q., Schaufeli, W. B., Taris, T., \& Schreurs, B. (2012). For fun, love, or money: What drives workaholic, engaged, and burned-out employees at work? Applied Psychology: An International Review, 61, 30-55.

van Beek, I., Taris, T. W., \& Schaufeli, W. B. (2011). Workaholic and work engaged employees: Dead ringers or worlds apart? Journal of Occupational Health Psychology, 16, 468-482.

Van den Broeck, A., Schreurs, B., De Witte, H., Vansteenkiste, M., Germeys, F., \& Schaufeli, W. (2011). Understanding workaholics' motivations: A self-determination perspective. Applied Psychology: An International Review, 60, 600-621.

Zapf, D. (2002). Emotion work and psychological well-being: A review of the literature and some conceptual considerations. Human Resource Management Review, 12, 237-268.

Zapf, D., Vogt, C., Seifert, C., Mertini, H., \& Isic, A. (2002). Emotion work as a source of stress: The concept and development of an instrument. European Journal of Work and Organizational Psychology, 8, 371-400.

Zohar, D., Tzischinski, O., \& Epstein, R. (2003). Effects of energy availability on immediate and delayed emotional reactions to work events. Journal of Applied Psychology, 88, 1082-1093. 


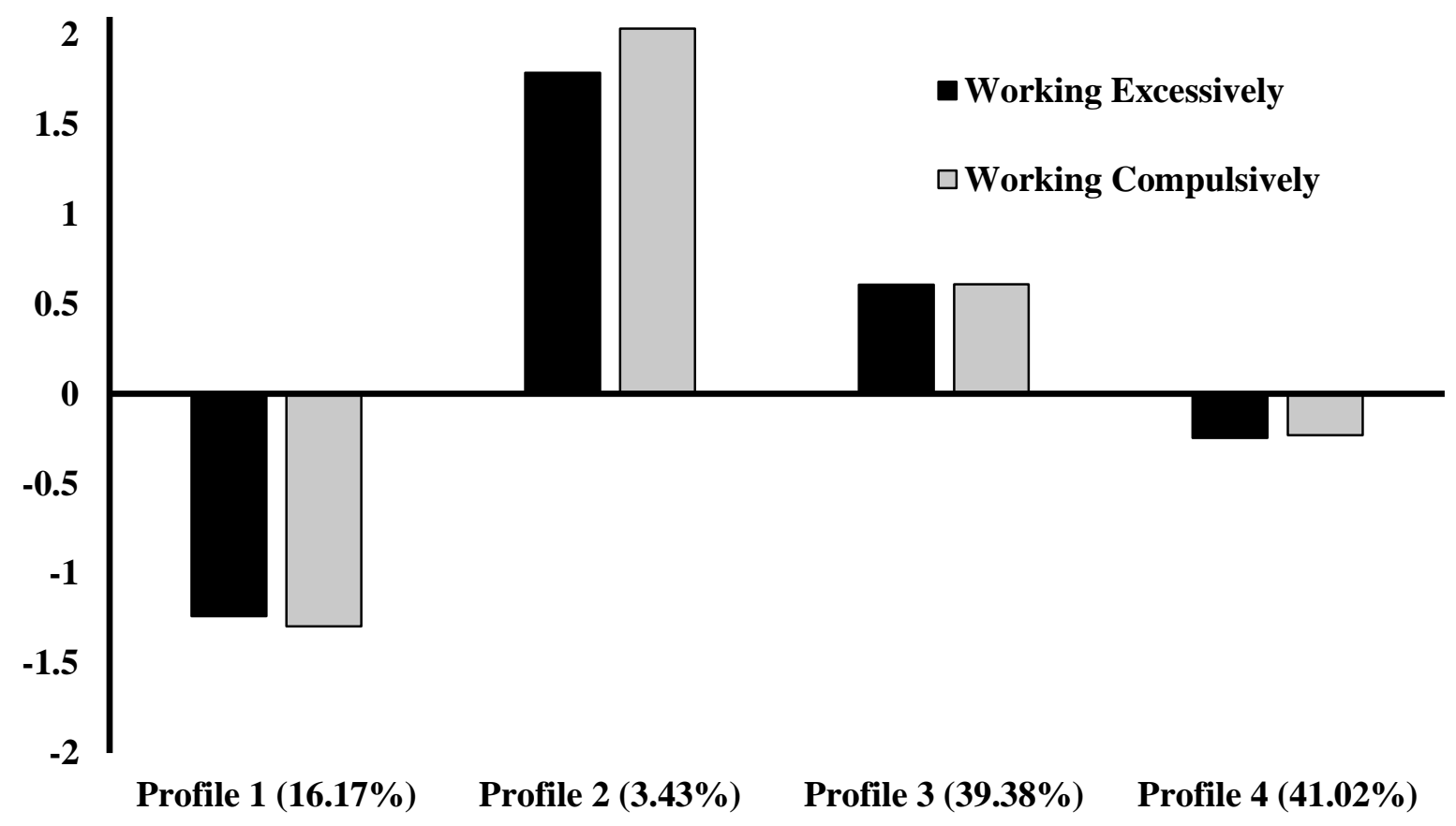

Figure 1a. Final four-profile solution (Study 1).

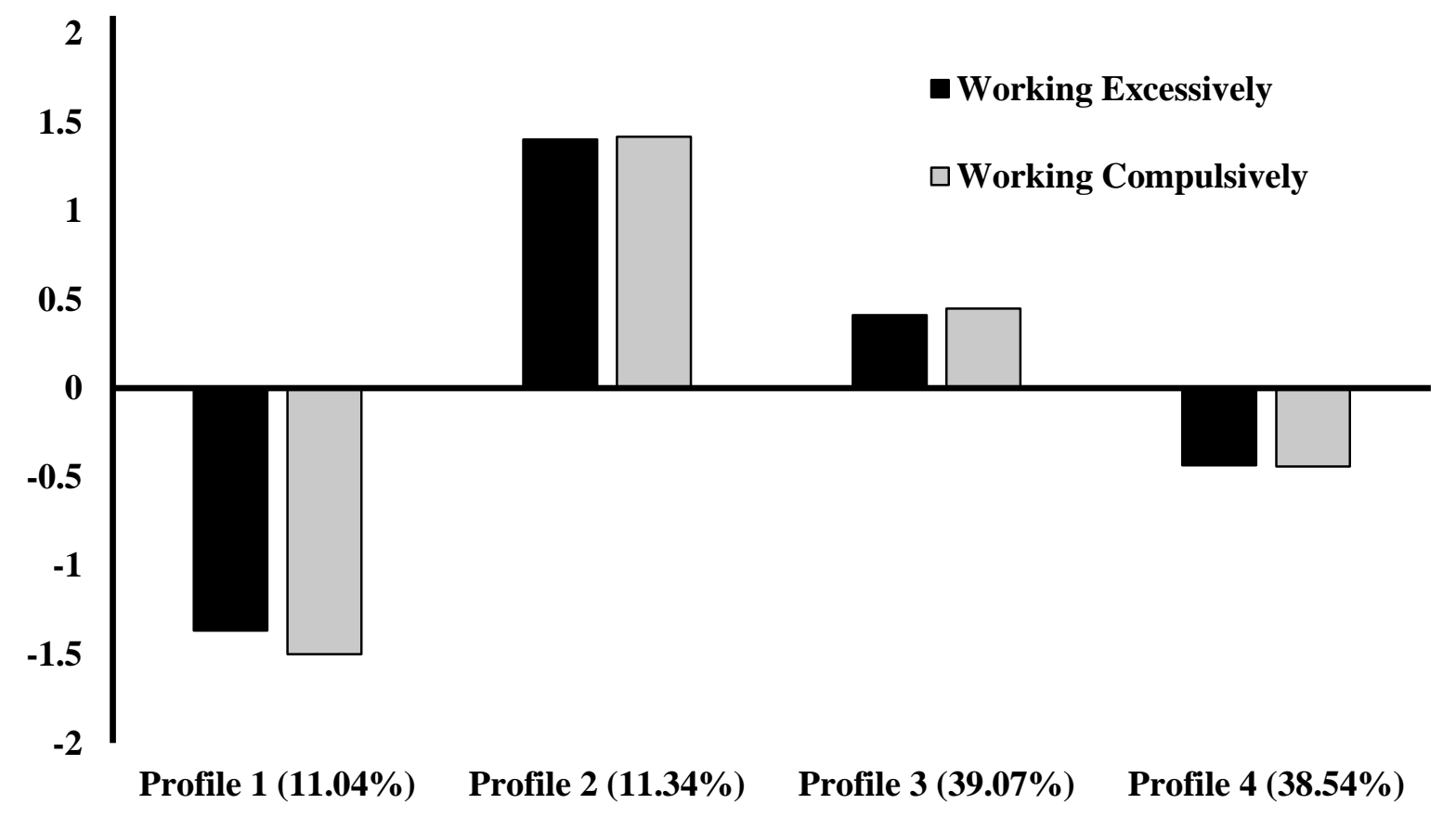

Figure 1b.

Figure 1. Final four-profile solution observed in Study 1 (Figure 1a) and Study 2 (Figure 1b). Note. The profile indicators are estimated from factor scores with mean of 0 and a standard deviation of 1; Profile 1: Very Low; Profile 2: Very High; Profile 3: Moderately High; Profile 4: Moderately Low. 


\section{Table 1}

Results from Multinomial Logistic Regressions for the Effects of the Predictors on Profile Membership

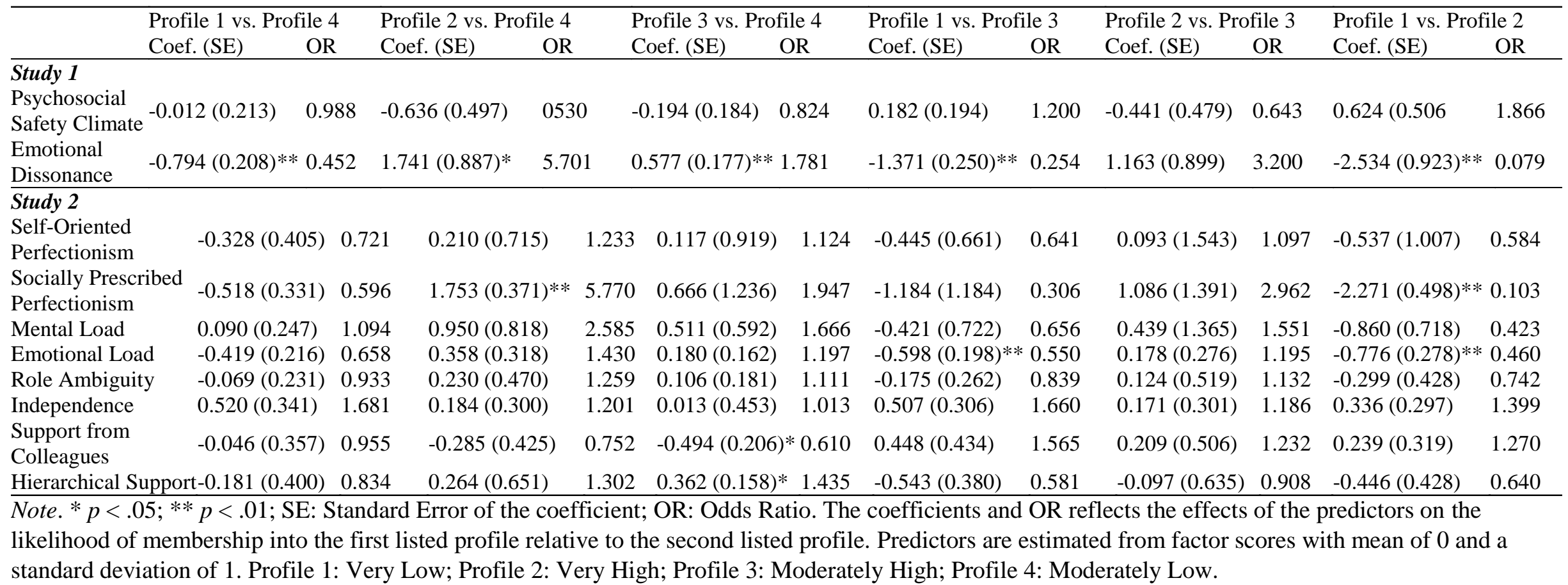


Table 2

Associations between Profile Membership, the Correlates, and the Outcomes

\begin{tabular}{|c|c|c|c|c|c|}
\hline & $\begin{array}{l}\text { Profile } 1 \\
\mathrm{M}[\mathrm{CI}]\end{array}$ & $\begin{array}{l}\text { Profile } 2 \\
\mathrm{M}[\mathrm{CI}]\end{array}$ & $\begin{array}{l}\text { Profile } 3 \\
\mathrm{M}[\mathrm{CI}]\end{array}$ & $\begin{array}{l}\text { Profile } 4 \\
\mathrm{M}[\mathrm{CI}]\end{array}$ & $\begin{array}{c}\text { Summary of Significant } \\
\text { Differences }\end{array}$ \\
\hline \multicolumn{6}{|l|}{ Study 1: Correlates } \\
\hline Competence Need Thwarting & $-0.337[-0.549 ;-0.125]$ & $0.512[-0.135 ; 1.159]$ & $0.234[0.105 ; 0.363]$ & $-0.050[-0.173 ; 0.073]$ & $2=3>1 ; 2=4>1 ; 3>4$ \\
\hline Autonomy Need Thwarting & $-0.553[-0.778 ;-0.328]$ & $0.681[0.113 ; 1.249]$ & $0.362[0.239 ; 0.485]$ & $-0.185[-0.305 ;-0.065]$ & $2=3>4>1$ \\
\hline Relatedness Need Thwarting & $-0.106[-0.322 ; 0.110]$ & $0.319[-0.273 ; 0.911]$ & $0.148[0.019 ; 0.277]$ & $-0.030[-0.161 ; 0.101]$ & $3>1 ; 1=2=4 ; 2=3=4$ \\
\hline \multicolumn{6}{|l|}{ Study 2: Correlates } \\
\hline Competence Need Thwarting & $-0.552[-0.785 ;-0.319]$ & $0.541[0.339 ; 0.743]$ & $0.128[0.030 ; 0.226]$ & $-0.139[-0.241 ;-0.037]$ & $2>3>4>1$ \\
\hline Autonomy Need Thwarting & $-0.568[-0.793 ;-0.343]$ & $0.567[0.359 ; 0.775]$ & $0.184[0.086 ; 0.282]$ & $-0.131[-0.227 ;-0.035]$ & $2>3>4>1$ \\
\hline Relatedness Need Thwarting & $-0.478[-0.678 ;-0.278]$ & $0.438[0.230 ; 0.646]$ & $0.164[0.066 ; 0.262]$ & $-0.082[-0.178 ; 0.014]$ & $2>3>4>1$ \\
\hline \multicolumn{6}{|l|}{ Study 1: Outcomes } \\
\hline Work-Family Conflict & $-0.668[-0.829 ;-0.507]$ & $0.981[0.573 ; 1.389]$ & $0.397[0.274 ; 0.520]$ & $-0.129[-0.243 ;-0.015]$ & $2>3>4>1$ \\
\hline Emotional Exhaustion & $-0.675[-0.844 ;-0.506]$ & $1.301[0.911 ; 1.691]$ & $0.411[0.293 ; 0.529]$ & $-0.157[-0.263 ;-0.051]$ & $2>3>4>1$ \\
\hline Perceived Stress & $-0.472[-0.656 ;-0.288]$ & $1.067[0.648 ; 1.486]$ & $0.254[0.136 ; 0.372]$ & $-0.110[-0.226 ; 0.006]$ & $2>3>4>1$ \\
\hline Turnover Intentions & $-0.168[-0.333 ;-0.003]$ & $0.840[0.423 ; 1.257]$ & $0.190[0.070 ; 0.310]$ & $0.029[-0.081 ; 0.139]$ & $2>3>4>1$ \\
\hline Psychological Detachment & $0.641[0.474 ; 0.808]$ & $-0.892[-1.270 ;-0.514]$ & $-0.327[-0.447 ;-0.207]$ & $0.115[-0.005 ; 0.235]$ & $1>4>3>2$ \\
\hline Job Satisfaction & $0.229[0.051 ; 0.407]$ & $-0.718[-1.161 ;-0.275]$ & $-0.179[-0.302 ;-0.056]$ & $0.053[-0.063 ; 0.169]$ & $1=4>3>2$ \\
\hline Perceived Health & $0.192[0.000 ; 0.384]$ & $-0.496[-0.943 ;-0.049]$ & $-0.177[-0.306 ;-0.048]$ & $0.099[-0.023 ; 0.221]$ & $1=4>3=2$ \\
\hline \multicolumn{6}{|l|}{ Study 2: Outcomes } \\
\hline Work-Family Conflict & $-1.062[-1.187 ;-0.937]$ & $0.967[0.828 ; 1.106]$ & $0.243[0.159 ; 0.327]$ & $-0.312[-0.400 ;-0.224]$ & $2>3>4>1$ \\
\hline Emotional Exhaustion & $-0.712[-0.863 ;-0.561]$ & $0.933[0.778 ; 1.088]$ & $0.162[0.060 ; 0.264]$ & $-0.207[-0.295 ;-0.119]$ & $2>3>4>1$ \\
\hline Life Satisfaction & $0.404[0.235 ; 0.573]$ & $-0.311[-0.507 ;-0.115]$ & $-0.120[-0.224 ;-0.016]$ & $0.064[-0.042 ; 0.170]$ & $1>4>3=2$ \\
\hline Perceived Health & $0.255[0.088 ; 0.422]$ & $-0.295[-0.477 ;-0.113]$ & $-0.153[-0.249 ;-0.057]$ & $0.115[0.019 ; 0.211]$ & $1=4>3=2$ \\
\hline
\end{tabular}

Note. M: Mean; CI: 95\% Confidence Interval. Correlates and outcomes are estimated from factor scores with mean of 0 and a standard deviation of 1. Profile 1: Very Low; Profile 2: Very High; Profile 3: Moderately High; Profile 4: Moderately Low. 
Online Supplemental Materials for:

Workaholism Profiles: Associations with Determinants, Correlates, and Outcomes 


\section{Preliminary Measurement Models}

For both studies, preliminary measurement models were estimated using Mplus 7.4 (Muthén \& Muthén, 2016). Due to the complexity of the measurement models underlying all constructs assessed here, these preliminary analyses were conducted separately for the workaholism variables and the correlates (i.e., psychological need thwarting) on the one hand, and the covariates (predictors and outcomes) on the other hand. The decision to rely on this specific grouping of variables is based on the fact that the measurement of workaholism and of the correlates was strictly parallel across studies, providing us with the possibility to conduct tests of measurement invariances across studies.

For Studies 1 and 2, an Exploratory Structural Equation Modeling (ESEM; Morin, Marsh, \& Nagengast, 2013) model was used to represent the two a priori workaholism factors (working excessively and compulsively) and the three a priori need thwarting factors (autonomy, competence, and relatedness). This decision is based on recent recommendations suggesting that ESEM is helpful for the assessment of conceptually-related constructs (the various facets of workaholism, and the various dimensions of need thwarting) assessed with the same instrument (Morin, Arens, \& Marsh, 2016; Morin, Boudrias et al., 2016). Results from statistical research (Asparouhov \& Muthén, 2009; Marsh, Lüdtke, Nagengast, Morin, \& Von Davier, 2013; Morin, Arens et al., 2016; Sass \& Schmitt, 2010; Schmitt \& Sass, 2011) showed that forcing cross-loadings (even as small as .100) present in the population model to be exactly zero (as in confirmatory factor analyses; CFA) results in an inflation of the factor correlations. In contrast, these same studies show that the free estimation of crossloadings, even when none are present in the population model, still provides unbiased estimates of the factor correlations (for a review, see Asparouhov, Muthén, \& Morin, 2015). These ESEM models were specified using a confirmatory approach based on target rotation (Asparouhov \& Muthén, 2009; Browne, 2001), which allows for the pre-specification of target loadings in a confirmatory manner, while cross-loadings are targeted to be as close to zero as possible. This model included two separate sets of correlated ESEM factors, with cross-loadings allowed between the various facets of each construct (workaholism or need thwarting) but not across facets of different construct.

In contrast, due to the relatively conceptually distinct nature of the various measures of the predictors and outcomes, based on distinct measurement instruments, measured in Study 1, this model was estimated using a more classical confirmatory factor analytic (CFA) approach. This model included nine a priori correlated factors (psychosocial safety climate, emotional dissonance, workfamily conflict, psychological detachment, emotional exhaustion, job satisfaction, perceived stress, turnover intentions, and perceived health) defined by their a priori indicators, with no cross-loadings. In this model, two correlated uniquenesses were included to control for the methodological artefact due to the reversed-wording of two of the perceived stress items, and two of the perceived health items (Marsh, Abduljabbar et al., 2013; Marsh, Scalas, \& Nagengast, 2010).

In Study 2, two different sets of correlated ESEM factors were used to reflect the conceptuallyrelated nature of the various dimensions of the two instruments used to assess the predictors: (a) two facets of perfectionism (self-oriented and socially prescribed) and (b) six facets of job demands and resources (mental load, emotional load, role ambiguity, independence, support from colleagues, and hierarchical support). This model also included a series of four correlated CFA factors reflecting the distinct nature of the outcomes which were all assessed with different instruments (emotional exhaustion, life satisfaction, perceived health, and work-family conflict). Overall, these 12 factors were allowed to correlate with one another, and cross-loadings were allowed within each set of ESEM factors, but not across these sets. No cross loadings was allowed for the CFA factors, and no correlated uniqueness was included in the model. The sets of ESEM factors were specified using target rotation, allowing for the pre-specification of target loadings in a confirmatory manner, while cross-loadings are targeted to be as close to zero as possible.

All of these measurement models were estimated with the robust weighted least square estimator (WLSMV). The choice to rely on WLSMV estimation is linked to the fact that this estimator is more suited to the ordered-categorical nature of the Likert scales used in the present study than traditional maximum likelihood (ML) estimation or robust alternatives (MLR) (Finney \& DiStefano, 2013), especially when the response categories follow asymmetric thresholds (as is the case for most measures used in this study). In these conditions, WLSMV estimation has been found to outperform ML/MLR (Bandalos, 2014; Beauducel \& Herzberg, 2006; Finney \& DiStefano, 2013; Flora \& Curran, 2004; Lubke \& Muthén, 2004; Rhemtulla, Brosseau-Liard, \& Savalei, 2012). 
We also verified that the measurement model for the workaholism and need thwarting variables operated in the same manner across studies through tests of measurement invariance (Millsap, 2011; Morin et al., 2011): (1) configural invariance, (2) weak invariance (loadings), (3) strong invariance (loadings and thresholds), (4) strict invariance (loadings, thresholds, and uniquenesses), (5) invariance of the latent variances-covariances (loadings, thresholds, uniquenesses, and latent variancescovariances), and (6) latent means invariance (loadings, thresholds, uniquenesses, latent variancescovariances, and latent means). Given the known oversensitivity of the chi-square test of exact fit $\left(\chi^{2}\right)$ to sample size and minor model misspecifications (e.g., Marsh, Hau, \& Grayson, 2005), we relied on sample-size independent goodness-of-fit indices to describe the fit of the alternative models (Hu \& Bentler, 1999; Yu, 2002): the comparative fit index (CFI), the Tucker-Lewis index (TLI), as well as the root mean square error of approximation (RMSEA) and its $90 \%$ confidence interval. Values greater than .90 for the CFI and TLI indicate adequate model fit, although values greater than .95 are preferable. Values smaller than .08 or .06 for the RMSEA respectively support acceptable and excellent model fit. Like the chi square, chi square difference tests present a known sensitivity to sample size and minor model misspecifications so that recent studies suggest complementing this information with changes in CFI and RMSEA (Chen, 2007; Cheung \& Rensvold, 2002) in the context of tests of measurement invariance. A $\triangle \mathrm{CFI} / \mathrm{TLI}$ of .010 or less and a $\triangle \mathrm{RMSEA}$ of .015 or less between a more restricted model and the previous one supports the invariance hypothesis. Composite reliability coefficients associated with each of the a priori factors are calculated from the model standardized parameters using McDonald (1970) omega ( $\omega)$ coefficient:

$$
\omega=\frac{\left(\sum\left|\lambda_{i}\right|\right)^{2}}{\left[\left(\sum\left|\lambda_{i}\right|\right)^{2}+\sum \delta_{i}\right]}
$$

where $\left|\lambda_{i}\right|$ are the standardized factor loadings associated with a factor in absolute values, and $\delta i$, the item uniquenesses. The numerator, were the factor loadings are summed, and then squared, reflects the proportion of the variance in in indicators that reflect true score variance, whereas the denominator reflects total amount of variance in the items including both true score variance and random measurement errors (reflects by the sum of the items uniquenesses associated with a factor).

The goodness-of-fit results for all models are reported in Table S1. These results support the adequacy of the a priori models (with all CFI/TLI $\geq .95$ and all RMSEA $\leq .08$ for the workaholism and need thwarting models; and all CFI/TLI $\geq .95$ and all RMSEA $\leq .06$ for the predictors and outcomes models). The parameter estimates and reliability from the workaholism and need thwarting model estimated in Study 1 are reported in Table S2. These results show that all factors are relatively well-defined through satisfactory factor loadings $(\lambda=.342$ to .995$)$, resulting in low to acceptable model-based composite reliability coefficient, ranging from $\omega=.589$ to .878 . The fact that one of the factor resulted in a slightly below typical acceptability levels reinforces the need to rely on a method providing at least a partial level of control for measurement errors. The results (see Table S1) also support the complete measurement invariance across both studies for the workaholism and need thwarting model as none of the changed in goodness-of-fit indices exceeded the recommended cut-off scores $(\Delta \mathrm{CFI} \leq .010 ; \Delta \mathrm{TLI} \leq .010 ; \Delta \mathrm{RMSEA} \leq .015)$, suggesting that the parameter estimates from this model obtained in Study 2 can be considered to be equivalent to those obtained in Study 1.

The final parameter estimates from the predictors/outcomes models, together with reliability information, are reported in Table S3 for Study 1 and in Table S4 for Study 2. These results again show that all factors are well-defined through satisfactory factor loadings (Study $1: \lambda=.378$ to .960 ; Study $2: \lambda=.347$ to .986 ), resulting in low to acceptable model-based composite reliability coefficient, ranging from $\omega=.738$ to .958 for Study 1 and $\omega=.710$ to .930 for Study 2 . The correlations between all variables used in the main analyses (i.e., the factor scores saved from these final measurement models) in both studies are reported in the main manuscript.

\section{References used in this supplement}

Asparouhov, T., \& Muthén, B. O. (2009). Exploratory structural equation modeling. Structural Equation Modeling, 16, 397-438.

Asparouhov, T., Muthén, B., \& Morin, A. J. S. (2015). Bayesian structural equation modeling with cross-loadings and residual covariances: Comments on Stromeyer et al. Journal of Management, $41,1561-1577$.

Bandalos, D. L. (2014). Relative performance of categorical diagonally weighted least squares and 
robust maximum likelihood estimation. Structural Equation Modeling, 21, 102-116.

Beauducel, A., \& Herzberg, P. (2006). Performance of maximum likelihood versus means and variance adjusted weighted least squares estimation in CFA. Structural Equation Modeling, 13, 186-203.

Browne, M. W. (2001). An overview of analytic rotation in exploratory factor analysis. Multivariate Behavioral Research, 36, 111-150.

Chen, F. F. (2007). Sensitivity of goodness of fit indexes to lack of measurement. Structural Equation Modeling, 14, 464-504.

Cheung, G. W., \& Rensvold, R. B. (2002). Evaluating goodness-of fit indexes for testing measurement invariance. Structural Equation Modeling, 9, 233-255.

Finney, S. J., \& DiStefano, C. (2013). Non-normal and categorical data in structural equation modeling. In G. R. Hancock, \& R. O. Mueller (Eds), Structural equation modeling: A second course, $2^{\text {nd }}$ edition (pp. 439-492). Greenwich, CO: IAP.

Flora, D. B., \& Curran, P. J. (2006). An empirical evaluation of alternative methods of estimation for confirmatory factor analysis with ordinal data. Psychological Methods, 9, 466-491.

Hu, L.-T., \& Bentler, P. M. (1999). Cutoff criteria for fit indexes in covariance structure analysis: Conventional criteria versus new alternatives. Structural Equation Modeling, 6, 1-55.

Lubke, G., \& Muthén, B. (2004). Applying multigroup confirmatory factor models for continuous outcomes to Likert scale data complicates meaningful group comparisons. Structural Equation Modeling, 11, 514-534.

Marsh, H. W., Abduljabbar, A. S., Abu-Hilal, M., Morin, A. J. S., Abdelfattah, F., Leung, K. C., Xu, M. K., Nagengast, B., \& Parker, P. (2013). Factor structure, discriminant and convergent validity of TIMSS math and science motivation measures: A comparison of USA and Saudi Arabia. Journal of Educational Psychology, 105, 108-128.

Marsh, H. W., Hau, K., \& Grayson, D. (2005). Goodness of fit in structural equation models. In A. Maydeu-Olivares, \& J.J. McArdle (Eds.), Contemporary psychometrics: A festschrift for Roderick P. McDonald (pp. 275-340). Mahwah, NJ: Erlbaum.

Marsh, H. W., Lüdtke, O., Nagengast, B., Morin, A. J. S., \& Von Davier, M. (2013). Why item parcels are (almost) never appropriate: Two wrongs do not make a right-Camouflaging misspecification with item parcels in CFA models. Psychological Methods, 18, 257-284.

Marsh, H. W., Scalas, L. F., \& Nagengast, B. (2010). Longitudinal tests of competing factor structures for the Rosenberg self-esteem scale: Traits, ephemeral artifacts, and stable response styles. Psychological Assessment, 22, 366-381.

McDonald, R. (1970). Theoretical foundations of principal factor analysis, canonical factor analysis, and alpha factor analysis. British Journal of Mathematical \& Statistical Psychology, 23, 1-21.

Millsap, R. (2011). Statistical approaches to measurement invariance. New York: Taylor \& Francis.

Morin, A. J. S., Arens, A. K., \& Marsh, H. W. (2016). A bifactor exploratory structural equation modeling framework for the identification of distinct sources of construct-relevant psychometric multidimensionality. Structural Equation Modeling, 23, 116-139.

Morin, A. J. S., Boudrias, J.-S., Marsh, H. W., McInerney, D. M., Dagenais-Desmarais, V., \& Madore, I. (2016). Complementary variable- and person-centered approaches to exploring the dimensionality of psychometric constructs: Application to psychological wellbeing at work. Journal of Business and Psychology. Early view: doi: 10.1007/s10869-016-9448-7.

Morin, A. J. S., Marsh, H. W., \& Nagengast, B. (2013). Exploratory structural equation modeling. In G. R. Hancock, \& R. O. Mueller (Eds.). Structural equation modeling: A second course (2nd ed.). Charlotte, NC: Information Age Publishing.

Morin, A. J. S., Moullec, G., Maïano, C., Layet, L., Just. J.-L., \& Ninot, G. (2011). Psychometric properties of the Center for Epidemiologic Studies Depression Scale (CES-D) in French clinical and non-clinical adults. Epidemiology and Public Health, 59, 327-340.

Muthén, L. K., \& Muthén, B. O. (2016). Mplus user's guide. Los Angeles, CA: Muthén \& Muthén.

Rhemtulla, M., Brosseau-Liard, P. É., \& Savalei, V. (2012). When can categorical variables be treated as continuous? A comparison of robust continuous and categorical SEM estimation methods under suboptimal conditions. Psychological Methods, 17, 354-373.

Sass, D. A., \& Schmitt, T. A. (2010). A comparative investigation of rotation criteria within exploratory factor analysis. Multivariate Behavioral Research, 45, 73-103.

Schmitt, T. A., \& Sass, D. A. (2011). Rotation criteria and hypothesis testing for exploratory factor 
analysis: Implications for factor pattern loadings and interfactor correlations. Educational \& Psychological Measurement, 71, 95-113.

Yu, C. Y. (2002). Evaluating cutoff criteria of model fit indices for latent variable models with binary and continuous outcomes. Los Angeles, CA: University of California.

\section{Selecting the Optimal Number of Profiles}

To determine the optimal number of profiles in the data, multiple sources of information need to be considered, including the examination of the substantive meaningfulness, theoretical conformity, and statistical adequacy of the solutions (Bauer \& Curran, 2003; Marsh, Lüdtke, Trautwein, \& Morin, 2009; Muthén, 2003). Statistical indices are available to support this decision (McLachlan \& Peel, 2000): (i) The Akaike Information Criterion (AIC), (ii) the Consistent AIC (CAIC), (iii) the Bayesian Information Criterion (BIC), (iv) the sample-size Adjusted BIC (ABIC), (v) the standard and adjusted Lo, Mendel and Rubin's (2001) Likelihood Ratio Tests (LMR/aLMR, as these tests typically yield the same conclusions, we only report the aLMR), and (vi) the Bootstrap Likelihood Ratio Test (BLRT). A lower value on the AIC, CAIC, BIC and ABIC suggests a better-fitting model. The aLMR and BLRT compare a $k$-class model with a $k$ - 1 -class model. A significant $p$ value indicates that the $k$ - 1 -class model should be rejected in favor of a $k$-class model. Finally, the entropy indicates the precision with which the cases are classified into the various profiles. The entropy should not be used to determine the optimal number of profiles (Lubke \& Muthén, 2007), but provides a useful summary of the classification accuracy, varying from 0 to 1 , with higher values indicating more accuracy.

Simulation studies indicate that four of indicators (CAIC, BIC, ABIC, and BLRT) are particularly effective (Henson, Reise, \& Kim, 2007; Nylund, Asparouhov, \& Muthén 2007; Peugh \& Fan, 2013; Tein, Coxe, \& Cham, 2013; Tofighi \& Enders, 2008; Yang, 2006), while the AIC and LMR/ALMR should not be used as they respectively tend to over- and under- extract incorrect number of profiles (Diallo, Morin, \& Lu, 2016; Henson et al., 2007; Nylund et al., 2007; Peugh \& Fan, 2013; Tofighi \& Enders, 2008; Yang, 2006). These indicators will still be reported to ensure a complete disclosure and to allow for comparisons with previous profile analyses reported in this literature, but will not be used to select the optimal number of profiles. In addition, a recent simulation study (Diallo et al., 2016) suggest that the BIC and CAIC should be privileged under conditions of high entropy (e.g., $\geq .800$ ), whereas the ABIC and BLRT appear to perform better in conditions of low entropy (e.g., $\leq .600$ ). It should be noted that all of these tests remain heavily influenced by sample size (Marsh et al., 2009), so that with sufficiently large sample sizes, they may keep on suggesting the addition of profiles without ever reaching a minimum. In these cases, information criteria should be graphically presented through "elbow plots" illustrating the gains associated with additional profiles (Morin, Maïano et al., 2011). In these plots, the point after which the slope flattens suggests the optimal number of profiles.

\section{Study 1}

The fit indices associated with the alternative LPA solutions are reported in the top section of Table S7 of these online supplements. These results shows that the CAIC, BIC, and BLRT all support a 5-profile solution, whereas the ABIC keeps on decreasing until it reaches the 7-profile solution. Entropy level is generally high, suggesting that a greater focus on the CAIC and BIC relative to the $\mathrm{ABIC}$ and BLRT is desirable. Still, in accordance with previous recommendations underscoring the need to accompany this statistical information by a careful examination of the parameters estimates associated with the various solutions, we contrasted the 5-profile solution with the adjacent 4- and 6profile solutions. The examination of these various solutions showed that these solutions were all fully proper statistically. The parameter estimates associated with these various solutions simply suggest that adding latent profiles to the 4-profile solution simply resulted in the arbitrary division of already existing profiles into new profiles presenting the same global shape and corresponding to 10 or fewer participants. Based on this information, the 4-profile solution was retained for interpretation.

\section{Study 2}

The fit indices associated with the alternative LPA solutions are reported in the bottom section of Table S7 of these online supplements. These results shows that the CAIC reaches its lowest point for the 5-profile solution, whereas the BIC reaches as similarly low point for the 5-and 6-profile solutions. In contrast, both the ABIC and the BLRT keep on suggesting the addition of latent profiles to the data without ever reaching a minimum point, which could potentially be explained by the larger sample size available in Study 2 relative to Study 1. In addition, entropy level is generally high, suggesting that a greater focus on the CAIC and BIC relative to the ABIC and BLRT is desirable. 
Given the lack of a clear minimal point, we also complemented this information by the examination of an elbow plot (Morin, Maïano et al., 2011), reported in Figure S1 of these online supplements. This plot shows that the relative improvement in fit associated with the addition of latent profiles appears to reach a clear plateau after the 4-profile solution, supporting the conclusions from Study 1. Still, like in Study 1, we conducted a careful examination of the 4-, 5-, and 6- profiles solutions, which all proved to be fully proper statistically, and substantively identical to the corresponding solutions from Study 1 . On the basis of this examination, the 4-profile was again retained as the final solution.

\section{References used in this supplement}

Bauer, D. J., \& Curran, P. J. (2003). Distributional assumptions of growth mixture models overextraction of latent trajectory classes. Psychological Methods, 8, 338-363.

Diallo, T. M. O, Morin, A. J. S., \& Lu, H. (2016b). The impact of total and partial inclusion or exclusion of active and inactive time invariant covariates in growth mixture models. Psychological Methods. Advance online publication. doi: 10.1037/met0000084

Henson, J. M., Reise, S. P., \& Kim, K. H. (2007). Detecting mixtures from structural model differences using latent variable mixture modeling: A comparison of relative model fit statistics. Structural Equation Modeling, 14, 202-226.

Lo, Y., Mendell, N., \& Rubin, D. (2001). Testing the number of components in a normal mixture. Biometrika, 88, 767-778.

Lubke, G., \& Muthén, B. O. (2007). Performance of factor mixture models as a function of model size, covariate effects, and class-specific parameters. Structural Equation Modeling, 14, $26-47$.

Marsh, H. W., Lüdtke, O., Trautwein, U., \& Morin, A. J. S. (2009). Classical latent profile analysis of academic self-concept dimensions: Synergy of person- and variable-centered approaches to theoretical models of self-concept. Structural Equation Modeling, 16, 191-225.

McLachlan, G., \& Peel, D. (2000). Finite mixture models. New York, NY: Wiley.

Morin, A. J. S., Maïano, C., Nagengast, B., Marsh, H. W., Morizot, J., \& Janosz, M. (2011). Growth mixture modeling of adolescents trajectories of anxiety: The impact of untested invariance assumptions on substantive interpretations. Structural Equation Modeling, 18, 613-648.

Muthén, B. O. (2003). Statistical and substantive checking in growth mixture modeling: Comment on Bauer and Curran (2003). Psychological Methods, 8, 369-377.

Nylund, K. L., Asparouhov, T., \& Muthén, B. (2007). Deciding on the number of classes in latent class analysis and growth mixture modeling: A Monte Carlo simulation study. Structural Equation Modeling, 14, 535-569.

Peugh, J., \& Fan, X. (2013). Modeling unobserved heterogeneity using latent profile analysis: A Monte Carlo simulation. Structural Equation Modeling, 20, 616-639.

Tein, J.-Y., Coxe, S., \& Cham, H. (2013). Statistical power to detect the correct number of classes in latent profile analysis. Structural Equation Modeling, 20, 640-657.

Tofighi, D., \& Enders, C. (2008). Identifying the correct number of classes in growth mixture models. In G. R. Hancock, \& K. M. Samuelsen (Eds.), Advances in latent variable mixture models (pp. 317-341). Charlotte, NC: Information Age.

Yang, C. (2006). Evaluating latent class analyses in qualitative phenotype identification. Computational Statistics \& Data Analysis, 50, 1090-1104. 


\section{Table S1}

Goodness-of-Fit Statistics of the Preliminary Measurement Models

\begin{tabular}{|c|c|c|c|c|c|c|c|c|c|}
\hline Description & $\chi^{2}(d f)$ & CFI & TLI & RMSEA & $90 \% \mathrm{CI}$ & $\operatorname{MD} \Delta \chi^{2}(d f)$ & $\Delta \mathrm{CFI}$ & $\Delta \mathrm{TLI}$ & $\overline{\Delta \text { RMSEA }}$ \\
\hline \multicolumn{10}{|c|}{ Workaholism and Correlates Measurement Models } \\
\hline Study $1(\mathrm{~N}=465)$ & $163.517(64)^{*}$ & .982 & .970 & .058 & {$[.047 ; .069]$} & - & - & - & - \\
\hline Study $2(\mathrm{~N}=780)$ & $331.422(64)^{*}$ & .974 & .958 & .073 & {$[.066 ; .081]$} & - & - & - & - \\
\hline Configural invariance $(\mathrm{N}=1245)$ & $473.434(128)^{*}$ & .978 & .964 & .066 & {$[.060 ; .072]$} & - & - & - & - \\
\hline Weak invariance & $469.778(154)^{*}$ & .980 & .973 & .057 & {$[.052 ; .063]$} & $28.411(26)$ & +.002 & +.009 & -.009 \\
\hline Strong invariance & $565.052(224)^{*}$ & .979 & .980 & .049 & {$[.044 ; .055]$} & $127.255(70)^{*}$ & -.001 & +.007 & -.008 \\
\hline Strict invariance & $658.455(239)^{*}$ & .974 & .977 & .053 & {$[.048 ; .058]$} & $111.613(15)^{*}$ & -.005 & -.003 & +.004 \\
\hline Latent variance-covariance invariance & $527.422(254)^{*}$ & .983 & .986 & .042 & {$[.037 ; .047]$} & $31.974(15)^{*}$ & +.009 & +.009 & -.011 \\
\hline \multicolumn{10}{|c|}{ Predictors and Outcomes Measurement Models } \\
\hline Study $1(\mathrm{~N}=465)$ & $1844.779(822)^{*}$ & .966 & .963 & .052 & {$[.049 ; .055]$} & - & - & - & - \\
\hline Study $2(\mathrm{~N}=780)$ & $2631.869(1062)^{*}$ & .962 & .954 & .044 & {$[.041 ; .046]$} & - & - & - & - \\
\hline
\end{tabular}

Note. $* p<.01 ; \chi^{2}$ : WLSMV chi-square test of exact fit; $d f$ : degrees of freedom; CFI: comparative fit index; TLI: Tucker-Lewis index; RMSEA: root mean square error of approximation; $90 \%$ CI: $90 \%$ confidence interval; MD $\Delta \chi^{2}$ : chi-square difference tests calculated with Mplus' DIFFTEST function. 


\section{Table S2}

Standardized Factor Loadings $(\lambda)$ and Uniquenesses $(\delta)$ for the Workaholism and Correlates

Measurement Models (Study 1)

\begin{tabular}{|c|c|c|c|c|c|c|}
\hline Items & $\begin{array}{c}\text { Factor } 1 \\
\lambda\end{array}$ & $\begin{array}{c}\text { Factor } 2 \\
\lambda\end{array}$ & $\begin{array}{c}\text { Factor } 3 \\
\lambda\end{array}$ & $\begin{array}{c}\text { Factor } 4 \\
\lambda\end{array}$ & $\begin{array}{c}\text { Factor } 5 \\
\lambda\end{array}$ & $\delta$ \\
\hline \multicolumn{7}{|c|}{ 1. Working Excessively } \\
\hline Item 1 & .756 & -.044 & & & & .469 \\
\hline Item 2 & .342 & .188 & & & & .764 \\
\hline Item 3 & .525 & .146 & & & & .605 \\
\hline$\omega$ & .589 & & & & & \\
\hline \multicolumn{7}{|c|}{ 2. Working Compulsively } \\
\hline Item 1 & -.192 & .995 & & & & .221 \\
\hline Item 2 & .073 & .606 & & & & .570 \\
\hline Item 3 & .351 & .526 & & & & .360 \\
\hline$\omega$ & & .797 & & & & \\
\hline \multicolumn{7}{|c|}{ 3. Competence Need Thwarting } \\
\hline Item 1 & & & .984 & -.001 & -.203 & .240 \\
\hline Item 2 & & & 698 & .070 & .221 & .204 \\
\hline Item 3 & & & .445 & .107 & .356 & .392 \\
\hline$\omega$ & & & .844 & & & \\
\hline \multicolumn{7}{|c|}{ 4. Autonomy Need Thwarting } \\
\hline Item 1 & & & .337 & .511 & -.032 & .460 \\
\hline Item 2 & & & .010 & .853 & -.022 & .275 \\
\hline Item 3 & & & -.162 & .792 & .007 & .484 \\
\hline$\omega$ & & & & .792 & & \\
\hline \multicolumn{7}{|c|}{ 5. Relatedness Need Thwarting } \\
\hline Item 1 & & & .077 & .186 & .690 & .324 \\
\hline Item 2 & & & .126 & -.171 & .881 & .154 \\
\hline Item 3 & & & -.019 & .040 & .825 & .318 \\
\hline$\omega$ & & & & & .878 & \\
\hline
\end{tabular}

Note. $\lambda$ : factor loading; $\delta$ : item uniqueness; $\omega$ : omega coefficient of model-based composite reliability; target factor loadings for the ESEM factors are indicated in bold. 
Table S3

Standardized Factor Loadings ( $\lambda)$ and Uniquenesses $(\delta)$ for the Predictors and Outcomes Measurement Models (Study 1)

\begin{tabular}{|c|c|c|c|c|c|c|c|c|c|c|}
\hline Items & $\begin{array}{c}\text { Factor } 1 \\
\lambda\end{array}$ & $\begin{array}{c}\text { Factor } 2 \\
\lambda\end{array}$ & $\begin{array}{c}\text { Factor } 3 \\
\lambda\end{array}$ & $\begin{array}{c}\text { Factor } 4 \\
\lambda\end{array}$ & $\begin{array}{c}\text { Factor } 5 \\
\lambda\end{array}$ & $\begin{array}{c}\text { Factor } 6 \\
\lambda\end{array}$ & $\begin{array}{c}\text { Factor } 7 \\
\lambda\end{array}$ & $\begin{array}{c}\text { Factor } 8 \\
\lambda\end{array}$ & $\begin{array}{c}\text { Factor } 9 \\
\lambda\end{array}$ & $\delta$ \\
\hline Item 1 & .841 & & & & & & & & & .292 \\
\hline Item 2 & .846 & & & & & & & & & .284 \\
\hline Item 4 & .902 & & & & & & & & & .187 \\
\hline Item 5 & .902 & & & & & & & & & .186 \\
\hline Item 6 & .873 & & & & & & & & & .239 \\
\hline Item 7 & .709 & & & & & & & & & .497 \\
\hline Item 10 & .672 & & & & & & & & & .548 \\
\hline Item 11 & .771 & & & & & & & & & .406 \\
\hline Item 12 & .768 & & & & & & & & & .410 \\
\hline$\omega$ & .958 & & & & & & & & & \\
\hline \multicolumn{11}{|c|}{ 2. Emotional Dissonance } \\
\hline Item 1 & & .811 & & & & & & & & .342 \\
\hline Item 2 & & .715 & & & & & & & & .489 \\
\hline Item 1 & & & 906 & & & & & & & .180 \\
\hline Item 2 & & & .838 & & & & & & & .298 \\
\hline Item 3 & & & .915 & & & & & & & .162 \\
\hline$\omega$ & & & .917 & & & & & & & \\
\hline \multicolumn{11}{|c|}{ 4. Psychological Detachment } \\
\hline Item 1 & & & & .941 & & & & & & .115 \\
\hline Item 2 & & & & .953 & & & & & & .091 \\
\hline Item 3 & & & & .841 & & & & & & .293 \\
\hline Item 4 & & & & .857 & & & & & & .265 \\
\hline$\omega$ & & & & .944 & & & & & & \\
\hline
\end{tabular}




\begin{tabular}{|c|c|c|c|c|c|c|c|c|c|c|}
\hline Items & $\begin{array}{c}\text { Factor } 1 \\
\lambda\end{array}$ & $\begin{array}{c}\text { Factor } 2 \\
\lambda\end{array}$ & $\begin{array}{c}\text { Factor } 3 \\
\lambda\end{array}$ & $\begin{array}{c}\text { Factor } 4 \\
\lambda\end{array}$ & $\begin{array}{c}\text { Factor } 5 \\
\lambda\end{array}$ & $\begin{array}{c}\text { Factor } 6 \\
\lambda\end{array}$ & $\begin{array}{c}\text { Factor } 7 \\
\lambda\end{array}$ & $\begin{array}{c}\text { Factor } 8 \\
\lambda\end{array}$ & $\begin{array}{c}\text { Factor } 9 \\
\lambda\end{array}$ & $\delta$ \\
\hline \multicolumn{11}{|l|}{ 5. Emotional Exhaustion } \\
\hline Item 1 & & & & & .796 & & & & & .366 \\
\hline Item 2 & & & & & .769 & & & & & .408 \\
\hline Item 4 & & & & & .864 & & & & & .254 \\
\hline Item 5 & & & & & .886 & & & & & .215 \\
\hline$\omega$ & & & & & .911 & & & & & \\
\hline \multicolumn{11}{|l|}{ 6. Job Satisfaction } \\
\hline Item 3 & & & & & & .794 & & & & .370 \\
\hline$\omega$ & & & & & & .843 & & & & \\
\hline \multicolumn{11}{|l|}{ 7. Perceived Stress } \\
\hline Item 1 & & & & & & & .766 & & & .413 \\
\hline Item 2 & & & & & & & .378 & & & .857 \\
\hline Item 3 & & & & & & & .624 & & & .611 \\
\hline Item 4 & & & & & & & .769 & & & .409 \\
\hline$\omega$ & & & & & & & & .953 & & \\
\hline \multicolumn{11}{|l|}{ 9. Perceived Health } \\
\hline Item 1 & & & & & & & & & .860 & .261 \\
\hline Item 2 & & & & & & & & & .716 & .488 \\
\hline Item 3 & & & & & & & & & .847 & .283 \\
\hline Item 4 & & & & & & & & & .742 & .450 \\
\hline$\omega$ & & & & & & & & & .871 & \\
\hline
\end{tabular}

Note. $\lambda$ : factor loading; $\delta$ : item uniqueness; $\omega$ : omega coefficient of model-based composite reliability. 


\section{Table S4}

Standardized Factor Loadings ( $\lambda$ ) and Uniquenesses ( $\delta$ ) for the Predictors and Outcomes Measurement Models (Study 2)

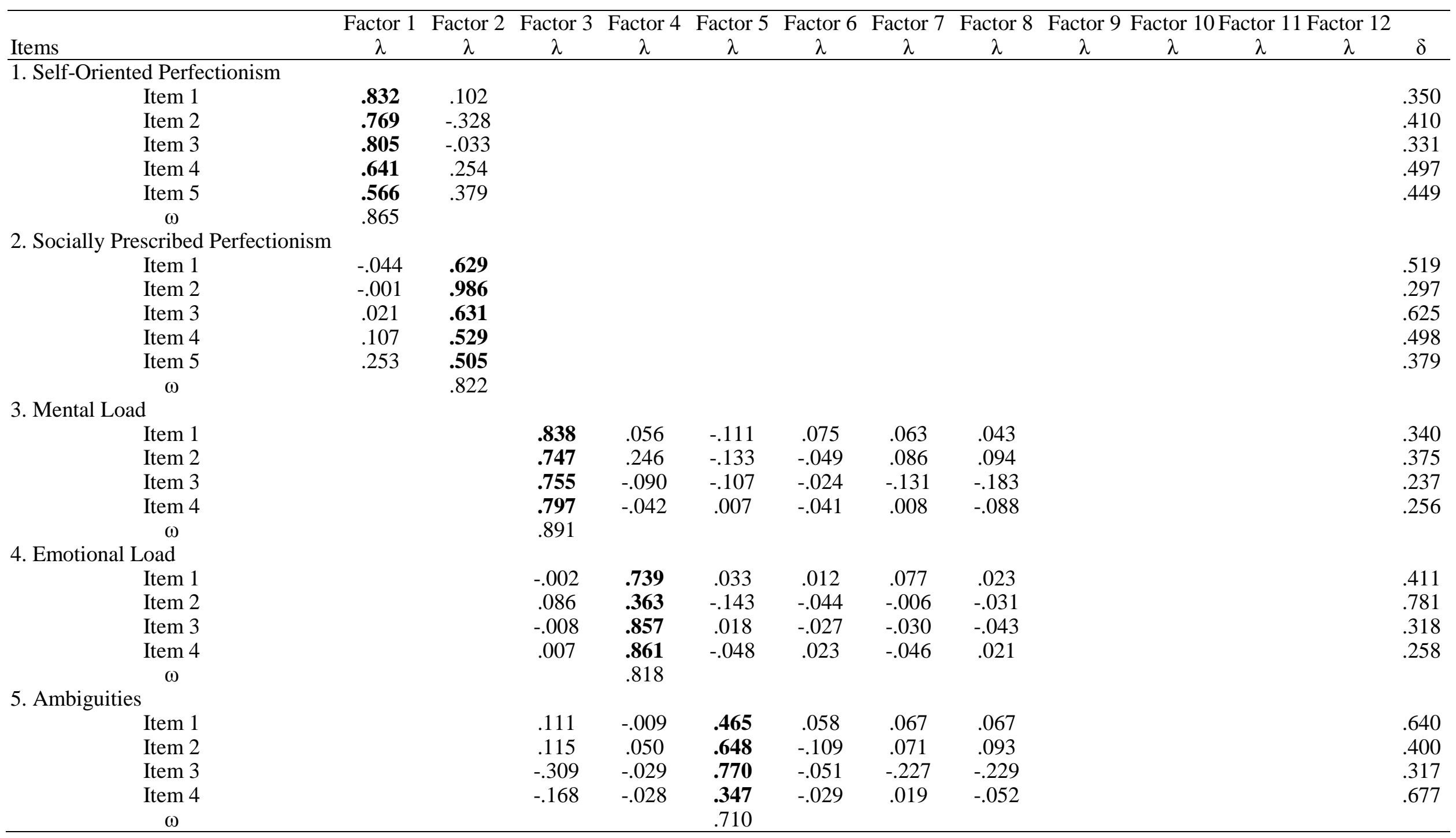




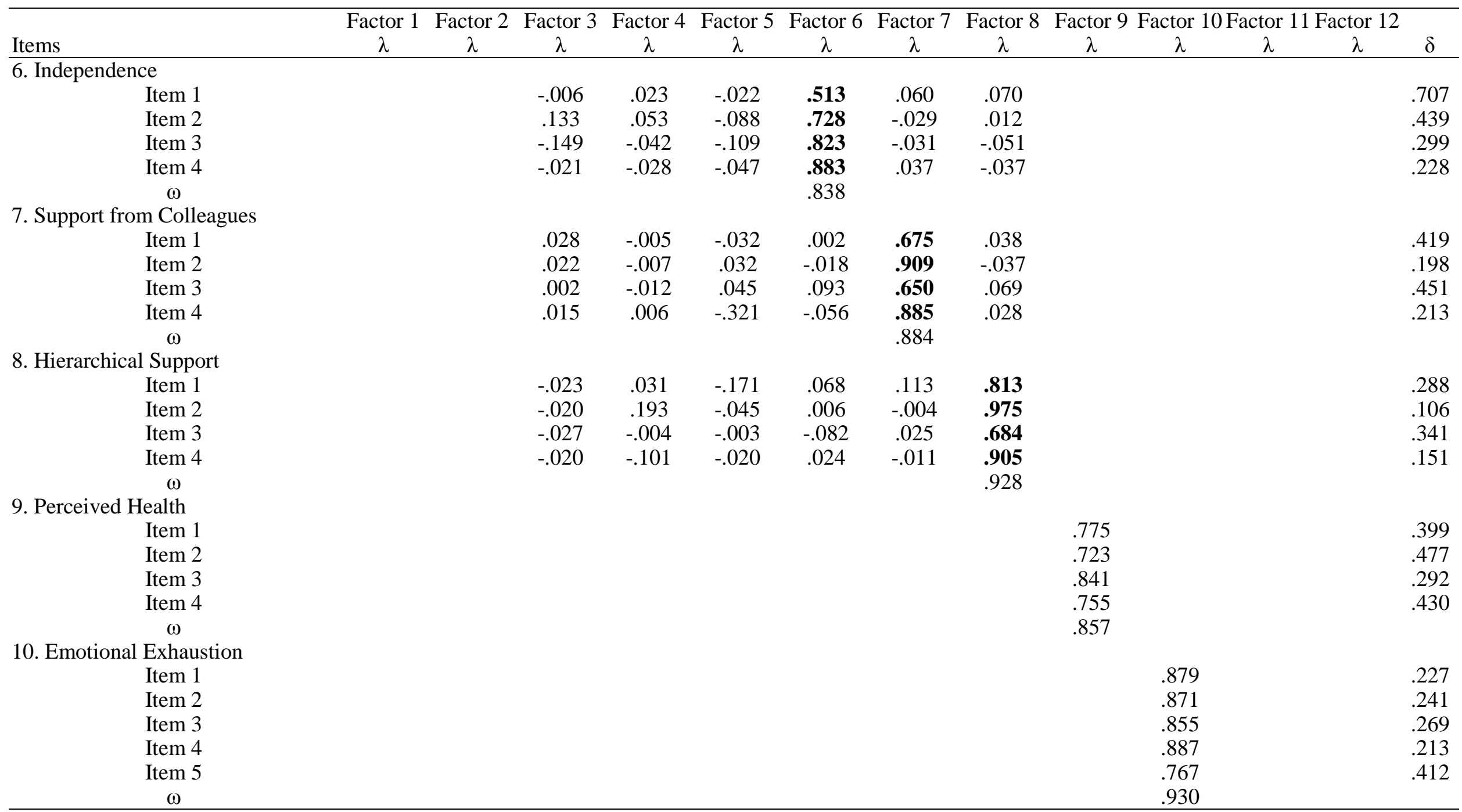




\begin{tabular}{|c|c|c|c|c|c|c|c|c|c|c|c|c|}
\hline Items & $\begin{array}{c}\text { Factor } 1 \\
\lambda\end{array}$ & $\begin{array}{c}\text { Factor } 2 \\
\lambda\end{array}$ & $\begin{array}{c}\text { Factor } 3 \\
\lambda\end{array}$ & $\begin{array}{c}\text { Factor } 4 \\
\lambda\end{array}$ & $\begin{array}{c}\text { Factor } 5 \\
\lambda\end{array}$ & $\begin{array}{c}\text { Factor } 6 \\
\lambda\end{array}$ & $\begin{array}{c}\text { Factor } 7 \\
\lambda\end{array}$ & $\begin{array}{c}\text { Factor } 8 \\
\lambda\end{array}$ & $\begin{array}{c}\text { Factor } 9 \\
\lambda\end{array}$ & $\begin{array}{ccc}\text { Factor } & 10 \text { Factor } \\
\lambda & \lambda\end{array}$ & $\begin{array}{c}11 \text { Factor } 12 \\
\lambda\end{array}$ & $\delta$ \\
\hline \multicolumn{13}{|l|}{ 11. Life Satisfaction } \\
\hline Item 1 & & & & & & & & & & .785 & & .384 \\
\hline Item 2 & & & & & & & & & & .839 & & .296 \\
\hline Item 4 & & & & & & & & & & .775 & & .399 \\
\hline Item 5 & & & & & & & & & & .723 & & .477 \\
\hline$\omega$ & & & & & & & & & & .900 & & \\
\hline \multicolumn{13}{|l|}{ 12. Work-Family Conflict } \\
\hline Item 3 & & & & & & & & & & & 911 & .170 \\
\hline$\omega$ & & & & & & & & & & & .906 & \\
\hline
\end{tabular}

Note. $\lambda$ : factor loading; $\delta$ : item uniqueness; $\omega$ : omega coefficient of model-based composite reliability; target factor loadings for the ESEM factors are indicated in bold. 
Table S5

Correlations between Variables (Study 1)

\begin{tabular}{|c|c|c|c|c|c|c|c|c|c|c|c|c|c|c|}
\hline Variable & 1 & 2 & 3 & 4 & 5 & 6 & 7 & 8 & 9 & 10 & 11 & 12 & 13 & 14 \\
\hline $\begin{array}{l}\text { 1. Psychosocial Safety } \\
\text { Climate }\end{array}$ & .958 & & & & & & & & & & & & & \\
\hline 2. Emotional Dissonance & $-.291 * *$ & .907 & & & & & & & & & & & & \\
\hline 3. Work-Family Conflict & $-.157 * *$ & $.406 * *$ & .917 & & & & & & & & & & & \\
\hline 4. Psychological Detachment & $.212 * *$ & $-.268 * *$ & $-.678 * *$ & .944 & & & & & & & & & & \\
\hline 5. Emotional Exhaustion & $-.362 * *$ & $.538 * *$ & $.492 * *$ & $-.344 * *$ & .911 & & & & & & & & & \\
\hline 6. Job Satisfaction & $.515 * *$ & $-.364 * *$ & $-.277 * *$ & $.117 *$ & $-.619 * *$ & .843 & & & & & & & & \\
\hline 7. Perceived Stress & $-.316 * *$ & $.489 * *$ & $.568 * *$ & $-.386 * *$ & $.630 * *$ & $-.503 * *$ & .738 & & & & & & & \\
\hline 8. Turnover Intentions & $-.464 * *$ & $.332 * *$ & $.195 * *$ & -.050 & $.521 * *$ & $-.747 * *$ & $.399 * *$ & .953 & & & & & & \\
\hline 9. Perceived Health & $.287 * *$ & $-.267 * *$ & $-.363 * *$ & $.284 * *$ & $-.600 * *$ & $.338 * *$ & $-.584 * *$ & $-.220 * *$ & .871 & & & & & \\
\hline 10. Working Excessively & $-.211 * *$ & $.432 * *$ & $.482 * *$ & $-.435 * *$ & $.529 * *$ & $-.239 * *$ & $.388 * *$ & $.228 * *$ & $-.247 * *$ & .589 & & & & \\
\hline 11. Working Compulsively & $-.112 *$ & $.367 * *$ & $.288 * *$ & $-.269 * *$ & $.356 * *$ & $-.151 * *$ & $.241 * *$ & $.157 * *$ & $-.102 *$ & $.773 * *$ & .797 & & & \\
\hline $\begin{array}{l}\text { 12. Competence Need } \\
\text { Thwarting }\end{array}$ & $-.339 * *$ & $.341 * *$ & $.293 * *$ & $-.169 * *$ & $.389 * *$ & $-.421 * *$ & $.394 * *$ & $.307 * *$ & $-.277 * *$ & $.277 * *$ & $.214 * *$ & .844 & & \\
\hline $\begin{array}{l}\text { 13. Autonomy Need } \\
\text { Thwarting }\end{array}$ & $-.278 * *$ & $.419 * *$ & $.299 * *$ & $-.213 * *$ & $.448 * *$ & $-.334 * *$ & $.365 * *$ & $.288 * *$ & $-.276^{* *}$ & $.492 * *$ & $.322 * *$ & $.632 * *$ & .792 & \\
\hline $\begin{array}{l}\text { 14. Relatedness Need } \\
\text { Thwarting }\end{array}$ & $-.270 * *$ & $.206 * *$ & $.258 * *$ & $-.165^{* *}$ & $.287 * *$ & $-.317 * *$ & $.300 * *$ & $.199 * *$ & $-.286^{* *}$ & $.156^{* *}$ & .087 & $.715 * *$ & $.358 * *$ & .878 \\
\hline
\end{tabular}


Table S6

Correlations between Variables (Study 2)

\begin{tabular}{|c|c|c|c|c|c|c|c|c|c|c|c|c|c|c|c|c|c|}
\hline Variable & 1 & 2 & 3 & 4 & 5 & 6 & 7 & 8 & 9 & 10 & 11 & 12 & 13 & 14 & 15 & 16 & 17 \\
\hline 1. Self-Oriented Perfectionism & .865 & & & & & & & & & & & & & & & & \\
\hline 2. Socially Prescribed Perfectionism & $.658 * *$ & .822 & & & & & & & & & & & & & & & \\
\hline 3. Mental Load & $.260 * *$ & $.141 * *$ & .891 & & & & & & & & & & & & & & \\
\hline 4. Emotional Load & $.170 * *$ & $.243 * *$ & $.501 * *$ & .818 & & & & & & & & & & & & & \\
\hline 5. Role Ambiguity & $-.130 * *$ & $.095 * *$ & $-.395 * *$ & $-.186 * *$ & .710 & & & & & & & & & & & & \\
\hline 6. Independence & $.122 * *$ & $-.151 * *$ & $.167 * *$ & .051 & $-.300 * *$ & .838 & & & & & & & & & & & \\
\hline 7. Support from Colleagues & $.094 * *$ & $-.241 * *$ & $.151 * *$ & -.040 & $-.362 * *$ & $.309 * *$ & .884 & & & & & & & & & & \\
\hline 8. Hierarchical Support & $.136 * *$ & $-.222 * *$ & $.086^{*}$ & $-.100 * *$ & $-.357 * *$ & $.324 * *$ & $.653 * *$ & .928 & & & & & & & & & \\
\hline 9. Perceived Health & .030 & $-.242 * *$ & $-.099 * *$ & $-.271 * *$ & $-.134 * *$ & $.223 * *$ & $.273 * *$ & $.331 * *$ & .857 & & & & & & & & \\
\hline 10. Emotional Exhaustion & $.162 * *$ & $.491 * *$ & $.213 * *$ & $.363 * *$ & $.114 * *$ & $-.299 * *$ & $-.412 * *$ & $-.500 * *$ & $-.507 * *$ & .930 & & & & & & & \\
\hline 11. Life Satisfaction & .016 & $-.195 * *$ & $.098 * *$ & -.007 & $-.232 * *$ & $.336 * *$ & $.326 * *$ & $.320 * *$ & $.390 * *$ & $-.433 * *$ & .900 & & & & & & \\
\hline 12. Work-Family Conflict & $.243 * *$ & $.444 * *$ & $.186^{* *}$ & $.344 * *$ & $.101 * *$ & $-.104 * *$ & $-.178 * *$ & $-.142 * *$ & $-.310 * *$ & $.562 * *$ & $-.283 * *$ & .906 & & & & & \\
\hline 13. Working Excessively & $.346 * *$ & $.520 * *$ & $.259 * *$ & $.288 * *$ & .016 & $-.140 * *$ & $-.174 * *$ & $-.142 * *$ & $-.225 * *$ & $.531 * *$ & $-.250 * *$ & $.598 * *$ & .605 & & & & \\
\hline 14. Working Compulsively & $.438 * *$ & $.421 * *$ & $.267 * *$ & $.252 * *$ & $-.071 *$ & $.071 *$ & -.035 & .058 & $-.109 * *$ & $.286 * *$ & $-.075^{*}$ & $.462 * *$ & $.818 * *$ & .778 & & & \\
\hline 15. Competence Need Thwarting & $.110 * *$ & $.456^{* *}$ & .046 & $.200 * *$ & $.244 * *$ & $-.297 * *$ & $-.447 * *$ & $-.457 * *$ & $-.309 * *$ & $.573 * *$ & $-.347 * *$ & $.384 * *$ & $.518 * *$ & $.204 * *$ & .810 & & \\
\hline 16. Autonomy Need Thwarting & $.075^{*}$ & $.380 * *$ & .066 & $.149 * *$ & $.155^{* *}$ & $-.345 * *$ & $-.262 * *$ & $-.361 * *$ & $-.257 * *$ & $.500 * *$ & $-.304 * *$ & $.323 * *$ & $.534 * *$ & $.159 * *$ & $.668 * *$ & .841 & \\
\hline 17. Relatedness Need Thwarting & $.125^{* *}$ & $.407 * *$ & -.029 & $.130 * *$ & $.206 * *$ & $-.219 * *$ & $-.525 * *$ & $-.362 * *$ & $-.293 * *$ & $.461 * *$ & $-.291 * *$ & $.339 * *$ & $.367 * *$ & $.226^{* *}$ & $.826 * *$ & $430 * *$ & .834 \\
\hline
\end{tabular}

Note. $* p<.05 ; * * p<.01$. Variables are factor scores from preliminary models with a mean of 0 and standard deviation of 1 . Composite reliability

coefficients are reported in bold, in the diagonal. 
Table S7

Results from the Latent Profile Analysis Models

\begin{tabular}{|c|c|c|c|c|c|c|c|c|c|c|}
\hline Model & $\mathrm{LL}$ & $\# f p$ & Scaling & AIC & CAIC & $\mathrm{BIC}$ & $\mathrm{ABIC}$ & Entropy & aLMR & BLRT \\
\hline \multicolumn{11}{|l|}{ Study 1} \\
\hline 1 Profile & -1192.468 & 4 & 0.9873 & 2392.936 & 2413.504 & 2409.504 & 2396.809 & $\mathrm{Na}$ & $\mathrm{Na}$ & $\mathrm{Na}$ \\
\hline 2 Profiles & -1085.770 & 9 & 1.2335 & 2189.541 & 2235.819 & 2226.819 & 2198.255 & 0.708 & 0.0030 & $<.001$ \\
\hline 3 Profiles & -1019.150 & 14 & 1.1024 & 2066.299 & 2138.288 & 2124.288 & 2079.855 & 0.738 & 0.0128 & $<.001$ \\
\hline 4 Profiles & -982.229 & 19 & 0.9462 & 2002.458 & 2100.157 & 2081.157 & 2020.855 & 0.802 & $<.001$ & $<.001$ \\
\hline 5 Profiles & -950.006 & 24 & 0.9220 & 1948.012 & 2071.421 & 2047.421 & 1971.251 & 0.828 & $<.001$ & $<.001$ \\
\hline 6 Profiles & -940.322 & 29 & 0.9280 & 1938.644 & 2087.763 & 2058.763 & 1966.724 & 0.840 & 0.0200 & 0.2069 \\
\hline 7 Profiles & -930.252 & 34 & 1.0064 & 1928.504 & 2103.333 & 2069.333 & 1961.425 & 0.834 & $<.001$ & 0.3750 \\
\hline 8 Profiles & -923.840 & 39 & 0.9235 & 1925.680 & 2126.219 & 2087.219 & 1963.443 & 0.869 & 0.0259 & 0.1622 \\
\hline \multicolumn{11}{|l|}{ Study 2} \\
\hline 1 Profile & -2027.466 & 4 & 1.0012 & 4062.932 & 4085.569 & 4081.569 & 4068.867 & $\mathrm{Na}$ & $\mathrm{Na}$ & $\mathrm{Na}$ \\
\hline 2 Profiles & -1828.274 & 9 & 1.1727 & 3674.548 & 3725.482 & 3716.482 & 3687.903 & 0.685 & $<.001$ & $<.001$ \\
\hline 3 Profiles & -1708.495 & 14 & 2.1192 & 3444.990 & 3524.220 & 3510.220 & 3465.763 & 0.737 & 0.3831 & $<.001$ \\
\hline 4 Profiles & -1626.320 & 19 & 1.3181 & 3290.639 & 3398.166 & 3379.166 & 3318.832 & 0.796 & 0.0058 & $<.001$ \\
\hline 5 Profiles & -1594.753 & 24 & 1.1588 & 3237.506 & 3373.329 & 3349.329 & 3273.117 & 0.798 & 0.0017 & $<.001$ \\
\hline 6 Profiles & -1577.469 & 29 & 1.0796 & 3212.939 & 3377.058 & 3348.058 & 3255.969 & 0.815 & 0.0061 & $<.001$ \\
\hline 7 Profiles & -1562.388 & 34 & 1.0057 & 3192.776 & 3385.192 & 3351.192 & 3243.225 & 0.759 & 0.0185 & $<.001$ \\
\hline 8 Profiles & -1546.395 & 39 & 1.0577 & 3170.790 & 3391.502 & 3352.502 & 3228.658 & 0.757 & 0.1977 & $<.001$ \\
\hline
\end{tabular}

Note. LL: model loglikelihood; \#fp: number of free parameters; scaling: scaling correction factor associated with robust maximum likelihood estimates; AIC: Akaïke information criteria; CAIC: constant AIC; BIC: Bayesian information criteria; ABIC: sample size adjusted BIC; aLMR: adjusted Lo-Mendel-Rubin likelihood ratio test; BLRT: bootstrap likelihood ratio test. 


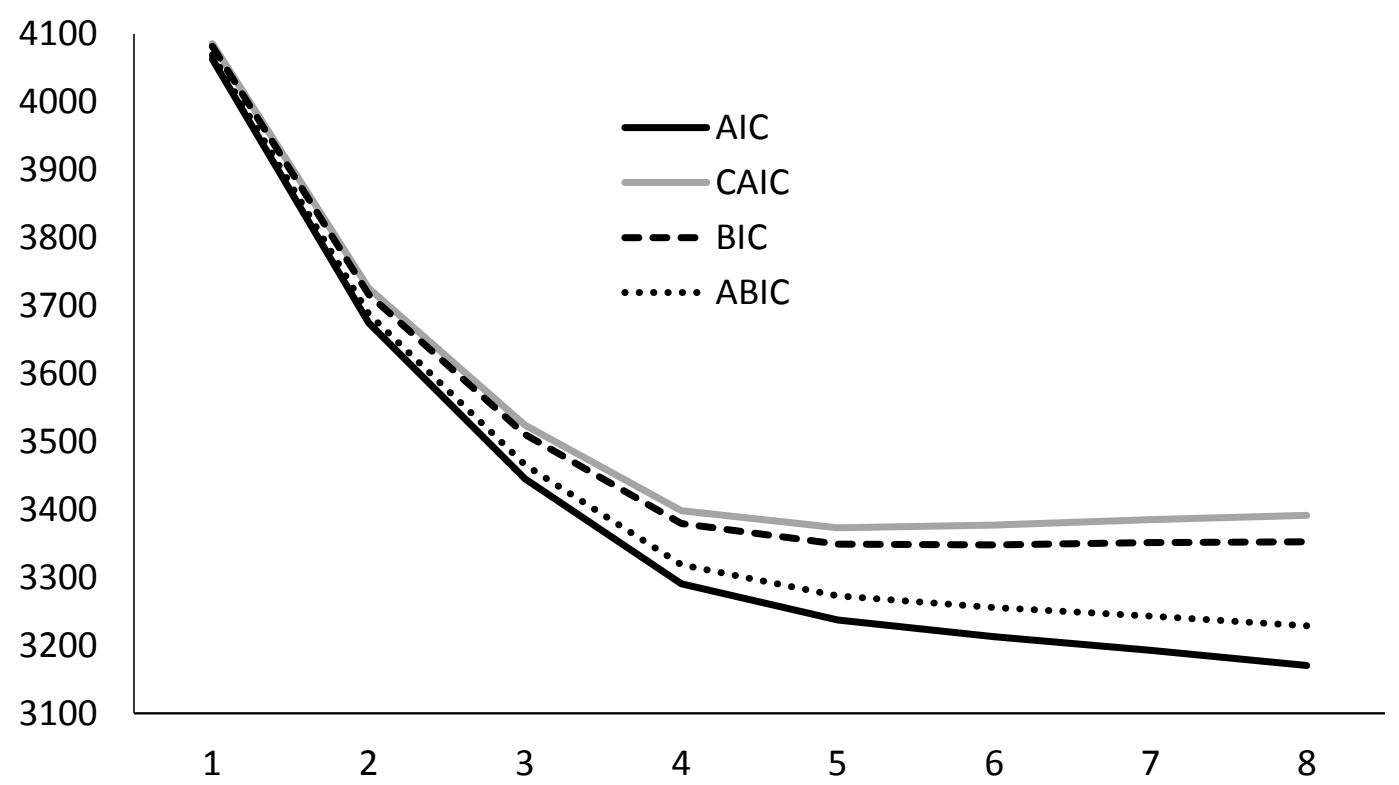

Figure S1. Elbow Plot of the Information Criteria for the Latent Profile Analyses (Study 2)

\section{Table S8}

Detailed Results from the Final Latent Profile Solution (Study 1)

\begin{tabular}{|c|c|c|c|c|}
\hline & $\begin{array}{c}\text { Profile } 1 \\
\text { Mean }[\mathrm{CI}]\end{array}$ & $\begin{array}{c}\text { Profile } 2 \\
\text { Mean [CI] }\end{array}$ & $\begin{array}{c}\text { Profile } 3 \\
\text { Mean [CI] }\end{array}$ & $\begin{array}{c}\text { Profile } 4 \\
\text { Mean }[\mathrm{CI}]\end{array}$ \\
\hline Working Excessively & $-1.239[-1.414 ;-1.064]$ & $1.789[1.607 ; 1.970]$ & $.607[.483 ; .732]$ & $-.246[-.387 ;-.104]$ \\
\hline Working Compulsively & $-1.295[-1.460 ;-1.131]$ & $2.035[1.811 ; 2.260]$ & $.610[.477 ; .721]$ & $-.230[-.385 ;-.074]$ \\
\hline & Variance $[\mathrm{CI}]$ & Variance $[\mathrm{CI}]$ & Variance $[\mathrm{CI}]$ & Variance $[\mathrm{CI}]$ \\
\hline Working Excessively & $.238[.175 ; .301]$ & $.105[.052 ; .158]$ & $.199[.148 ; .251]$ & $.158[.107 ; .209]$ \\
\hline Working Compulsively & $.197[.149 ; .244]$ & $.085[.011 ; 159]$ & $.258[.205 ; .311]$ & $.228[.177 ; .279]$ \\
\hline
\end{tabular}

\section{Table S9}

Detailed Results from the Final Latent Profile Solution (Study 2)

\begin{tabular}{lcccc}
\hline & Profile 1 & Profile 2 & Profile 3 & Profile 4 \\
& Mean [CI] & Mean [CI] & Mean [CI] & Mean [CI] \\
\hline Working Excessively & $-1.368[-1.658 ;-1.078]$ & $1.403[1.161 ; 1.644]$ & $.413[.219 ; .606]$ & $-.435[-.711 ;-.158]$ \\
Working Compulsively & $-1.499[-1.892 ;-1.106]$ & $1.419[1.056 ; 1.783]$ & $.449[.220 ; .679]$ & $-.441[-.676 ;-.206]$ \\
\hline & Variance [CI] & Variance [CI] & Variance [CI] & Variance [CI] \\
\hline Working Excessively & $.261[.189 ; .333]$ & $.175[.101 ; .248]$ & $.163[.107 ; .219]$ & $.198[.112 ; .285]$ \\
Working Compulsively & $.204[.072 ; .335]$ & $.357[.135 ; 580]$ & $.172[.082 ; .262]$ & $.150[.114 ; .187]$ \\
\hline
\end{tabular}

Note. $\mathrm{CI}=95 \%$ Confidence Interval. The profile indicators are estimated from factor scores with mean of 0 and a standard deviation of 1. Profile 1: Very Low; Profile 2: Very High; Profile 3: Moderately High; Profile 4: Moderately Low. 